\title{
POUNDS THAT KILL: THE EXTERNAL COSTS OF VEHICLE WEIGHT
}

\author{
Michael Anderson \\ Maximilian Auffhammer \\ Working Paper 17170 \\ http://www.nber.org/papers/w17170
NATIONAL BUREAU OF ECONOMIC RESEARCH
1050 Massachusetts Avenue
Cambridge, MA 02138
June 2011

We gratefully acknowledge support from the Robert Wood Johnson Foundation and the University of California Energy Institute. We thank Larry Goulder, Ryan Kellogg, Ian Parry and Ken Small for valuable feedback. Seminar participants at CESIfo Munchen, Duke University, UC Berkeley, the UC Energy Institute, UC Irvine, University of Michigan, Cornell University, RAND, NBER, and the Occasional Workshop on Environmental and Resource Economics have provided helpful comments. The views expressed herein are those of the authors and do not necessarily reflect the views of the National Bureau of Economic Research.

NBER working papers are circulated for discussion and comment purposes. They have not been peerreviewed or been subject to the review by the NBER Board of Directors that accompanies official NBER publications.

(C) 2011 by Michael Anderson and Maximilian Auffhammer. All rights reserved. Short sections of text, not to exceed two paragraphs, may be quoted without explicit permission provided that full credit, including $(\odot$ notice, is given to the source. 
Pounds that Kill: The External Costs of Vehicle Weight

Michael Anderson and Maximilian Auffhammer

NBER Working Paper No. 17170

June 2011

JEL No. H23,I18,Q48,Q58,R41

\begin{abstract}
$\underline{\text { ABSTRACT }}$
Heavier vehicles are safer for their own occupants but more hazardous for the occupants of other vehicles. In this paper we estimate the increased probability of fatalities from being hit by a heavier vehicle in a collision. We show that, controlling for own-vehicle weight, being hit by a vehicle that is 1,000 pounds heavier results in a $47 \%$ increase in the baseline fatality probability. Estimation results further suggest that the fatality risk is even higher if the striking vehicle is a light truck (SUV, pickup truck, or minivan). We calculate that the value of the external risk generated by the gain in fleet weight since 1989 is approximately 27 cents per gallon of gasoline. We further calculate that the total fatality externality is roughly equivalent to a gas tax of $\$ 1.08$ per gallon. We consider two policy options for internalizing this external cost: a gas tax and an optimal weight varying mileage tax. Comparing these options, we find that the cost is similar for most vehicles.
\end{abstract}

Michael Anderson

Department of Agricultural

and Resource Economics

207 Giannini Hall, MC 3310

University of California

Berkeley CA 94720-3310

mlanderson@berkeley.edu

Maximilian Auffhammer

Agricultural and Resource Economics Department

University of California, Berkeley

207 Giannini Hall

Berkeley, CA 94720-3310

and NBER

auffhammer@berkeley.edu 


\section{INTRODUCTION}

The average weight of light vehicles sold in the United States has fluctuated substantially over the past 35 years. From 1975 to 1980, average weight dropped almost 1,000 pounds (from 4,060 pounds to 3,228 pounds), likely in response to rising gasoline prices and the passage of the Corporate Average Fuel Efficiency (CAFE) standard. As gasoline prices fell in the late-1980s, however, average vehicle weight began to rise, and by 2005 it had attained 1975 levels (US EPA 2009). A rich body of research examines the effects of CAFE and gasoline prices on consumers' vehicle choices (Goldberg 1998; Portney et al. 2003; Kleit 2004; Austin and Dinan 2005; Klier and Linn 2008; Bento, Goulder, Jacobsen, and von Haefen, 2009; Busse, Knittel, and Zettelmeyer 2009; Li, Timmins, and Von Haefen 2009).

One question that remains unresolved is how traffic fatalities are affected by the choices consumers make in response to gasoline prices and fuel economy standards. Traffic accidents are the leading cause of death for persons under the age of 40 , and they are a major source of life-years lost. ${ }^{1}$ Intuitively, heavier cars are safer than lighter cars, and previous research has argued that a heavier vehicle fleet is a safer vehicle fleet (Crandall and Graham 1989). Much of the subsequent transportation safety literature has focused on the effects of average vehicle weight on safety, reaching varying conclusions. ${ }^{2}$ Jacobsen (2010) extends this literature by exploring the traffic safety implications of different fuel economy regulatory schemes across ten vehicle classes. The paper uses data on fatal accidents and concludes that tightening fuel economy standards will not increase fatalities as long as the standards are "footprint based" or unified across cars and trucks. ${ }^{3}$

\footnotetext{
1 Lung cancer, a disease that is generally the result of smoking, kills approximately four times as many Americans each year as traffic accidents. However, the average lung cancer decedent is 71 years old while the average traffic accident decedent is only 39 years old. The number of life-years lost to traffic accidents is thus similar in magnitude to the number of life-years lost to lung cancer.

2 Most of the transportation safety literature is based on time series correlations between average vehicle weight and aggregate fatality rates (Robertson 1991; Khazzoom 1994; Noland 2004, 2005; Ahmad and Greene 2005). Two exceptions are Kahane (2003) and Van Auken and Zellner (2005), which use micro data concerning fatal accidents only. They supplement the fatal accident data with data on police-reported accidents from several states to estimate the rate at which different types of vehicles enter into collisions. These studies come to varying conclusions regarding the sign of the relationship between average vehicle weight and overall fatality rates, but all conclude that the magnitude of the relationship is relatively modest.

3 If the current separation between cars and trucks is maintained and standards are not footprint based, Jacobsen estimates that raising CAFE standards by one mile per gallon could increase traffic fatalities by 149
} 
From an economic standpoint, however, an unregulated vehicle fleet must be inefficiently heavy. A heavier vehicle is safer for its own occupants but more hazardous for the occupants of other vehicles. The safety benefits of vehicle weight are therefore internal, while the safety costs of vehicle weight are external. Consumers' vehicle choices thus have the important features of an "arms race." To date no detailed attempt has been made to quantify the external costs of vehicle weight. This figure is essential for determining the socially optimal weight of the vehicle fleet, and it cannot be inferred from the net effects of average vehicle weight or fuel economy regulations on traffic safety.

We quantify the external costs of vehicle weight using a large micro data set on police-reported crashes for a set of 8 heterogeneous states. Unlike the data sets employed in the previous transportation literature or Jacobsen (2010), our data set includes both fatal and nonfatal accidents. Using unique vehicle identifiers (VINs), we determine the curb weight of each vehicle involved in an accident, thereby minimizing concerns about attenuation bias induced by measurement error. The rich set of vehicle, person, and accident observables in the data set allow us to minimize concerns about omitted variables bias. Using these data, we estimate the external effects of vehicle weight on fatalities and serious injuries conditional on a collision occurring.

Two key results emerge from our estimates. First, we show that vehicle weight is a critical determinant of fatalities in other vehicles in the event of a multivehicle collision; our preferred estimate implies that a 1,000 pound increase in striking vehicle weight raises the probability of a fatality in the struck vehicle by $47 \%$. When we translate this higher probability of a fatality into external costs (relative to a small baseline vehicle), the total external costs of vehicle weight from fatalities alone are estimated at $\$ 93$ billion per year. Second, by separately controlling for vehicle weight and whether the striking vehicle is a light truck (i.e., a pickup truck, sport utility vehicle, or minivan), we show that light trucks significantly raise the probability of a fatality in the struck car - in addition to the effect of their already higher vehicle weight.

Our unique data set allows us to condition on a collision occurring and thus ensures that our results cannot be generated by differences in collision rates between drivers of lighter and heavier vehicles. Nevertheless, driver selection could bias our results if drivers of

deaths per year. Jacobsen does not attempt to estimate the causal effect of vehicle weight on fatalities in other vehicles, which is the focus of this paper. 
heavy vehicles have a tendency towards severe accidents. We rule out this possibility through three tests. First, we show that vehicle weight does not predict fatalities when two vehicles of equal weight collide. This suggests that drivers of heavy vehicles are not predisposed towards severe accidents. Second, we show that our estimates persist even when controlling for specific vehicle type via make and model fixed effects. Finally, we instrument for striking vehicle weight using the number of occupants in the striking vehicle and find estimates that are close to our least squares estimates. All three tests suggest that we successfully identify the causal effect of vehicle weight on the probability of fatalities in two-car collisions.

One way to internalize the externality that we identify is through a weight varying mileage tax. However, such a tax could be logistically difficult to implement. We apply our estimates to consider whether a simple gasoline tax could be an alternative to internalize most of the external costs and conclude that it could. Our calculations suggest that the level of the optimal gasoline tax is substantially higher than previously estimated (e.g. Parry and Small 2005) and that the external traffic fatality costs of vehicle weight eclipse any other vehicle-related externality (Portney, Parry, Gruenspecht and Harrington, 2003).

The paper is organized as follows. Section 2 presents the analytic and empirical framework and discusses the previous literature. Section 3 details the data, and Section 4 presents the main results. Section 5 presents falsification tests and alternative sources of identification to check whether selection bias contaminates our results. Section 6 links the results to energy policy implications, focusing in particular on the gasoline tax. Section 7 concludes.

\section{ANALYTIC AND EMPIRICAL FRAMEWORK}

Consumers' vehicle choices represent a classic example of an externality driven “arms race.” Purchasing a heavier vehicle enhances safety for each individual, but also makes other roadway users less safe. The net benefit of vehicle weight on traffic fatalities is thus smaller than the private benefit of vehicle weight on traffic fatalities, and consumers are incentivized to purchase heavier vehicles than is socially optimal.

Figure 1 presents a stylized plot of the marginal private and social costs per mile of driving a heavier vehicle against the marginal private benefit per mile of driving a heavier vehicle. The marginal private cost of a heavier vehicle is positive due to the higher use of 
inputs to produce heavier vehicles (e.g. more steel, bigger tires, etc.) and the lower fuel efficiency of heavier vehicles. The marginal private benefit of a heavier vehicle is positive but decreasing in vehicle weight - heavier vehicles provide increased protection in a collision and more cargo capacity, but as size increases the vehicle becomes increasingly difficult to park and handle. ${ }^{4}$ The consumer equates marginal private cost and marginal private benefit and buys a vehicle weighing $\mathrm{W}^{*}$ pounds. The private operating cost per mile is $\mathrm{P}^{*}$. However, a heavier vehicle may impose a cost on other roadway users in the form of increased risk of fatalities in a collision with this vehicle, and the driver does not bear this external cost. If external costs increase linearly in vehicle weight, as we show is approximately the case, the social marginal cost curve lies above the private marginal cost curve by a fixed amount equal to the external per mile cost. To maximize social welfare, our stylized consumer should purchase a car weighing $\mathrm{W}^{* *}$ pounds, where $\mathrm{W}^{* *}<\mathrm{W}^{*}$. The necessary per-mile tax to induce this behavior is the marginal external cost of vehicle weight, $t^{*}$. If the consumer chooses a vehicle of weight $\mathrm{W}^{*}$, the external cost from this choice over the socially optimal choice of a vehicle weighing $\mathrm{W}^{* *}$ would be $\mathrm{t}^{*} \cdot\left(\mathrm{W}^{* *}-\mathrm{W}^{*}\right)$. We calculate this individual cost in Section 6 and aggregate it across all individuals to arrive at the total external costs.

It is important to note that the primary costs of this "arms race" accrue not in the form of traffic fatalities - which on net may change little with a reduction in fleet weight but rather in the form of purchases of larger vehicles that are more expensive to construct and operate. In this sense it is similar to a conventional arms race, which need not increase the probability of conflict even as both countries spend large amounts on new weapons. ${ }^{5}$

In principle, liability rules and insurance regulations could internalize many of the external costs due to vehicle weight. If drivers of heavy vehicles know that they will be held liable for deaths in other vehicles, then they should take these risks into account when purchasing their own vehicles. If insurance companies understand that heavier vehicles pose more danger to other roadway users, then they should charge higher liability premiums to drivers of heavy vehicles. In practice, however, liability rules and insurance regulations fail to internalize the fatality risks generated by heavy vehicles.

\footnotetext{
${ }^{4}$ At some point the marginal private benefits of weight become negative. For example, few drivers would want a 30 foot stretch limousine as their primary vehicle, even if it were luxuriously appointed and heavily subsidized.

5 Another example is the decision of a stadium spectator to sit or stand. If everyone stands, the average view is no better or worse than if everyone sits, but all spectators are less comfortable.
} 
Tort liability rules are inadequate to internalize fatality risks for two reasons. First, liability only applies in cases in which a driver behaves in a negligent manner (White 2004). This implies that the driver of any given vehicle will not always be liable in the event of a multivehicle accident. Second, even if found liable, few drivers possess assets that are sufficient to cover the cost of a fatality. The value of a statistical life (VSL) used by the United States Department of Transportation in cost-benefit analyses is \$5.8 million (2008 dollars), but only $7 \%$ of families in the United States had a net worth exceeding $\$ 1$ million in 2001 (Kennickell 2003).

Though few drivers can cover the cost of a fatality, liability insurance regulations could force most drivers to pay the expected liability costs of operating their vehicles. Again, however, the mandated levels of liability insurance are inadequate to cover the costs of a fatality. Two states (Florida and New Hampshire) do not require drivers to carry any liability coverage at all for injuries, and 44 states require drivers to carry $\$ 25,000$ or less in liability coverage for each person injured. Only five states require more than $\$ 25,000$ of liability coverage for each person injured (Insurance Information Institute 2010). ${ }^{6}$ Many drivers remain uninsured despite the regulations, and even drivers who carry more than the mandated minimums rarely have policies that exceed several hundred thousand dollars of coverage.

While liability rules and insurance regulations cannot internalize the majority of fatality costs, they may internalize a significant fraction of incapacitating injury costs. Estimates of the value of an incapacitating injury are far lower than the value of a statistical life, and it is plausible that insurance policies carried by many drivers could cover the costs of an incapacitating injury. ${ }^{7}$ For this reason, our policy analysis focuses on external fatality costs and ignores external incapacitating injury costs. Accounting for injury costs would increase the magnitude of our results, but we cannot accurately estimate what fraction of injury costs are already internalized. ${ }^{8}$

\footnotetext{
${ }^{6}$ Minnesota and North Carolina each require $\$ 30,000$ of liability coverage for each person injured, and Alaska, Maine, and Wisconsin each require $\$ 50,000$ of liability coverage for each person injured. None of these states are in our data set.

7 The National Safety Council, for example, estimates the comprehensive cost of an incapacitating injury at $\$ 214,000$ (2008 dollars). In comparison, the council estimates the comprehensive cost of a fatality at $\$ 4.2$ million.

8 The serious injury externality may be further mitigated by the fact that health insurers and the government pay for a portion of injury treatment costs. Drivers of heavy vehicles thus accrue a positive externality with respect to injuries that partially offsets the negative injury externality that they impose upon others.
} 
Previous work on the "arms race" on American roads has focused on the internal and external risks posed by the largest vehicles - pickup trucks and sport utility vehicles (SUVs) - relative to the typical passenger car. White (2004), Gayer (2004), Anderson (2008), and Li (forthcoming) all conclude that light trucks (pickups and SUVs) impose significant risks relative to passenger cars. This study expands upon that literature by considering the fundamental role that vehicle weight plays in determining external risk. We recognize that any vehicle that is heavier than the smallest feasible vehicle poses some external risk to other roadway users. We quantify that risk and find that the total external costs of vehicle weight substantially exceed the external costs that accrue only from light trucks. Our comprehensive results span the entire range of the vehicle fleet and allow us to consider the broader implications of vehicle weight for energy policy.

To measure the effect of vehicle weight on external fatalities under ideal conditions, we would randomly assign vehicles of differing weights to drivers and observe external fatality rates by vehicle type. Such an experiment is infeasible in practice, and even an analogous study using observational data is impractical due to substantial measurement error in vehicle stocks and model-level vehicle miles traveled in most states. Instead, we focus on the risk of a fatality conditional on a collision occurring. A key assumption when we interpret our estimates in a policy context is that vehicle weight has no causal effect on the probability of a collision. We discuss this assumption below and conclude that, if it is violated, then the effect of vehicle weight on the probability of a collision is likely positive. Our estimates thus represent a lower bound on the effect of weight on external fatalities.

Consider the expected external fatalities for a vehicle of type $i$ during time interval $t$. For simplicity, assume that $t$ is short enough that the probability of multiple collisions during $t$ is effectively zero.

$$
\mathrm{E}\left[\text { fatalities }_{i t}\right]=\mathrm{E}\left[\mathrm{E}\left[\text { fatalities }_{i t} \mid \text { collision }_{i t}\right]\right]=\mathrm{E}\left[\text { fatalities }_{i t} \mid \operatorname{collision}_{i t}\right] \cdot \mathrm{P}\left(\text { collision }_{i t}=1\right)
$$

Equation (1) must hold via the law of iterated expectations. It implies that if weight has no causal effect on the probability of a collision, then the total effect of weight on external fatalities is proportional to the effect of weight on external fatalities conditional on a collision occurring. Weight may affect the probability of a collision in two ways, however. First, from an engineering perspective, heavier vehicles are less maneuverable and have longer braking distances. Even if driver behavior is unchanged, heavier vehicles may 
therefore get into more accidents. Second, heavier vehicles may also affect driver behavior. On the margin, drivers may respond to the internal safety benefits of heavy vehicles by increasing their optimal collision rate (Peltzman 1975). Both the physical characteristics of heavier vehicles and the potential driver response to heavier vehicles could therefore generate a positive effect of vehicle weight on collision rates. ${ }^{9}$

Empirical evidence also suggests that, if anything, heavier vehicles have higher collision rates than lighter vehicles. Evans (1984) examines the relationship between accident rates and vehicle weight using accident data and vehicle registration data from North Carolina, New York, and Michigan. He finds that, after conditioning on driver age, 4,000 pound vehicles have accident rates that are 39\% higher than 2,000 pound vehicles. More recently, White (2004) and Anderson (2008) estimate that light trucks are 13\% to 45\% more likely to experience multivehicle collisions than passenger cars. Of course, some of the observed differences in crash rates may be due to driver selection; careless drivers may choose heavier vehicles. Nevertheless, both theory and empirical evidence suggest that weight may directly increase the probability of experiencing a collision. We thus interpret our estimates - which are conditional on a collision occurring - as lower bounds on the causal effect of weight on external fatalities. ${ }^{10}$

\section{DATA}

The data set consists of the population of police-reported accidents for eight states: Florida, Kansas, Kentucky, Maryland, Missouri, Ohio, Washington and Wyoming. These data come from the State Data System, maintained by the National Highway Traffic Safety Administration (NHTSA). We obtained permission from the head of each state's police force to use the data. The SDS data include information on injuries and fatalities, geographic

\footnotetext{
9 To the best of our knowledge, the only factor that might reduce the probability of a collision for heavier vehicles is visibility. Larger vehicles provide their drivers with a better view of the road ahead, which may decrease the probability of an accident. However, they also make it more difficult for drivers behind them to see ahead, which may increase the probability of an accident. The net impact of these two effects is unclear, but the resulting dynamic is again an example of an arms race - the visibility benefits are internal while the visibility costs are external. Visibility would thus be another reason to tax larger vehicles more than smaller vehicles. ${ }^{10}$ Note that the concern here is whether weight has a causal effect on collision probabilities. This concern arises because we consider the policy implications of inducing some drivers to switch to lighter vehicles via a tax. This exogenous manipulation of vehicle choice will affect collision probabilities only if vehicle weight has a causal effect on collision probabilities. Weight may also be correlated with the type of driver, which could generate selection bias in our regressions. We consider this issue separately in Section 5.
} 
location, weather conditions, use of safety equipment, and driver and occupant characteristics. We selected these eight states out of the 32 states currently participating in the SDS as they report the vehicle identification number (VIN) for the majority of vehicles in the data set. We purchased data tables from DataOne Software to match the first 9 digits of the VIN to curb weight data for each vehicle. We therefore observe curbside vehicle weight for approximately 64\% of the vehicles in our data set (we confirm in Section 4 that the missing weight data do not appear to bias our estimates). For analytic purposes, we decompose the data set into three sub-samples, two-vehicle crashes, three-vehicle crashes, and single-vehicle crashes. The two-vehicle crash data set is the focus of most of our analyses. It contains 4.8 million vehicles in collisions in which both vehicles have complete curbside weight data. ${ }^{11}$

One important feature of the SDS data is that accidents only appear in the data set if the police take an accident report. According to NHTSA documentation, various estimates suggest that only half of all motor vehicle accidents are police reported. While many of the unreported accidents are single vehicle accidents, some no doubt involve two vehicles as well. This sampling frame could affect our estimates if vehicle weight affects the probability of a police report, all other factors held constant. Serious multivehicle accidents are always reported to the police regardless of vehicle weight, but vehicle weight could affect the probability that a minor accident is reported to the police. Unlike the probability of a collision, there is no a priori reason to believe that vehicle weight must have a positive effect on the probability of a police report. On the one hand, collisions involving heavier vehicles cause more property damage, all other factors held constant, because more kinetic energy must be dissipated through deformation of materials. On the other hand, some heavier vehicles, such as pickup trucks, are more likely to be involved in rugged work. These trucks may have accumulated more dents, reducing the likelihood that the owners will report property damage from a minor accident.

If vehicle weight positively affects the reporting probability of minor accidents, then our estimates will represent a lower bound on the effect of weight on external fatalities. If vehicle weight negatively affects the reporting probability of minor accidents, however, then

\footnotetext{
11 The data set contains the population of police reported accidents for Florida (1989-2005), Kansas (20012005), Kentucky (1998-2005), Maryland (1989-1999), Missouri (1989-2005), Ohio (1991-2005), Washington (2002-2005), and Wyoming (1998-2005).
} 
our estimates of the effect of weight on external fatalities could be upwardly biased. To test whether the "ruggedness" hypothesis affects our results, we estimate our regressions while limiting the sample to collisions that do not involve any light trucks. This sample restriction does not reduce the coefficient estimates. ${ }^{12}$ We also conduct a series of falsification tests in Section 5 that imply that the sampling frame does not bias our results.

Table 1 presents summary statistics from our two-vehicle collision data set. This data set contains all collisions involving two light vehicles built after 1980. We define a light vehicle as any car, pickup truck, SUV, or minivan that weighs between 1,500 and 6,000 pounds. We exclude collisions involving heavy trucks. The first two columns report statistics for the entire two-vehicle collision data set. The mean vehicle weight in this data set is 3,076 pounds, and approximately $24.5 \%$ of vehicles are light trucks (pickups, SUVs, or minivans). The average model year is 1992, and the average number of occupants per vehicle is 1.41. The probability of a fatality in each vehicle is $0.19 \%$ (i.e., 0.0019), and the probability of a serious injury in each vehicle is $2.7 \%$. Alcohol is involved in $8.3 \%$ of collisions.

The last two columns of Table 1 report summary statistics for the estimation sample with complete covariates. This sample is smaller than the overall two-vehicle collision sample because we drop collisions in which any of the covariates from our preferred specification are missing. This restriction reduces the sample from 4.8 million observations to 2.8 million observations. Nevertheless, the two samples appear similar along most observable measures.

\section{SPECIFICATION AND RESUltS}

Consider a collision involving two vehicles, Vehicle 1 and Vehicle 2. Suppose that we label Vehicle 1 as the "struck vehicle" and Vehicle 2 as the "striking vehicle." These labels are for expositional purposes only - they do not signify which vehicle may be at fault in the collision. ${ }^{13}$ The external effects of vehicle weight are given by the effect of striking vehicle weight on the probability of fatalities in the struck vehicle. The internal effects of vehicle

\footnotetext{
${ }^{12}$ In the sample that excludes all collisions involving light trucks, the estimated effects are of similar magnitude to the analogous estimates from the main sample, reported in Table 2. This implies that the "ruggedness" hypothesis is not upwardly biasing our main results (see online Appendix Table A1).

13 The labels are symmetric in that each vehicle enters our data set twice, once as the striking vehicle and once as the struck vehicle.
} 
weight are given by the effect of struck vehicle weight on the probability of fatalities in the struck vehicle. The former is the quantity of policy interest, but we report results for the latter as well for comparison purposes.

We estimate the conditional expectation of a fatality in the struck vehicle as a function of striking vehicle weight, struck vehicle weight, and a rich set of covariates. We estimate the conditional expectation function (CEF) using either a linear probability model (LPM) or a probit. ${ }^{14}$ For robustness, we report estimates for both models.

We specify the linear probability model as follows:

$E\left[\right.$ struck veh fatality $_{i}$ I striking veh weight ${ }_{i}$, struck veh weight $\left.{ }_{i}, X_{1 i}, X_{2 i}, W_{i}\right]$

$=\beta_{1}$ striking veh weight $_{i}+\beta_{2}$ struck veh weight $_{i}+X_{1 i} \delta_{1}+X_{2 i} \delta_{2}+W_{i} \delta_{3}$

In equation (2), $\beta_{1}$ represents the coefficient of interest, $X_{1 i}$ represents a set of characteristics pertaining to the striking vehicle in collision $i, X_{2 i}$ represents a set of characteristics pertaining to the struck vehicle in collision $i$, and $W_{i}$ represents a set of characteristics common to both vehicles in collision $i$. The probit model modifies equation (2) as follows:

$E\left[\right.$ struck veh fatality $_{i} \mid$ striking veh weight ${ }_{i}$, struck veh weight $\left.{ }_{i}, X_{1 i}, X_{2 i}, W_{i}\right]$

$=\Phi\left(\alpha_{1}\right.$ striking veh weight $_{\mathrm{i}}+\alpha_{2}$ struck veh weight $\left._{i}+X_{1 i} \gamma_{1}+X_{2 i} \gamma_{2}+W_{i} \gamma_{3}\right)$

In equation (3), the link function $\Phi$ is the normal CDF. Therefore, the marginal effect of striking vehicle weight varies with striking vehicle weight. For comparability with the LPM results, for each probit regression we report the average marginal effect across all observations included in that regression. ${ }^{15}$

14 The LPM cannot literally be true. Nevertheless, it provides the minimum mean squared error linear approximation to the true CEF, and in our case the LPM coefficients are always close to the corresponding average marginal effects from the probit models.

15 Some of our probit regressions include fixed effects, raising the possibility of inconsistency due to the incidental parameters problem. However, in most cases we have many observations for each fixed effect, and as shown in Fernandez-Val (2009), the incidental parameters problem generates a trivial degree of bias in the probit model when estimating marginal effects (which are our quantities of interest). 
Table 2 presents results from estimating equations (2) and (3) on the two-vehicle collision data set. The sample includes all accidents for which there is complete vehicle weight data for both vehicles; analyses restricted to states with low rates of missing weight data suggest that this constraint does not bias our results. ${ }^{16}$ Each vehicle appears in the twovehicle collision data set twice, once as the struck vehicle and once as the striking vehicle. We therefore cluster the standard errors at the collision level to account for correlation between observations that pertain to the same collision.

The first and second columns in Table 2 include the following covariates: vehicle weight, light truck indicators, and year fixed effects. A striking vehicle and struck vehicle version of each of the first two variables is included. The first column implies that a 1,000 pound increase in weight in the striking vehicle is associated with a statistically significant 0.09 percentage point increase in the probability of a fatality in the struck vehicle $(t=22.0)$. This coefficient represents a $46 \%$ increase over the average probability of a fatality in a struck vehicle in this sample $(0.19 \%)$. In comparison, a 1,000 pound increase in weight in the struck vehicle is associated with a smaller 0.05 percentage point decrease in the probability of a fatality in the struck vehicle $(t=-11.8)$. Light trucks increase the probability of a fatality in the struck vehicle by 0.12 percentage points (62\% of the sample mean), even after controlling for striking vehicle weight $(t=19.5)$. The results from the probit model in

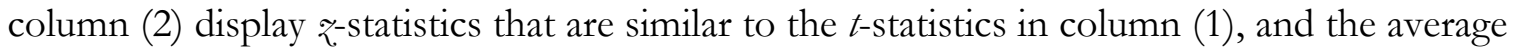
marginal effect generated by the probit model is of similar magnitude to the LPM coefficient (0.08 percentage points versus 0.09 percentage points).

Subsequent columns in Table 2 add additional covariates to the regressions. Columns (3) and (4) add controls for rain, darkness, day of week (weekday versus weekend), interstate highway, a quadratic in model year for each vehicle, and year, hour, and county fixed effects. The estimated effect of striking vehicle weight changes little in both the LPM and probit models. Columns (5) and (6) add controls for any seat belt usage, a quadratic in driver age, indicators for drivers under 21 or over 60, and indicators for male drivers or young male

\footnotetext{
${ }^{16}$ Weight data are missing for vehicles for which we do not have VINs. The percentage of vehicles with missing weight data ranges from $17.4 \%$ (Ohio) to $54.5 \%$ (Maryland). When estimating our main statistical models on the four states with the lowest rates of missing weight data (Kentucky, Ohio, Washington, and Wyoming), we find that an additional 1,000 pounds of striking vehicle weight increases the probability of a fatality in the struck vehicle by $46 \%$ to $51 \%$. When estimating the same models on the four states with highest rates of missing weight data (Florida, Kansas, Maryland, and Missouri), we find that an additional 1,000 pounds of striking vehicle weight increases the probability of a fatality in the struck vehicle by $44 \%$. The rate of missing weight data thus appears to have little impact on our estimates (see online Appendix Table A2).
} 
drivers. A striking vehicle and struck vehicle version of each of these variables is included. The inclusion of these driver characteristics has minimal impact on the primary coefficient of interest (striking vehicle weight). They do, however, increase the magnitude of the struck vehicle weight coefficient to -0.10 percentage points $(t=-20.2)$.

Column (7) of Table 2 adds city fixed effects and is our preferred specification. City fixed effects should absorb any geographic heterogeneity in fatality rates that could be correlated with average vehicle weight. This issue would arise if, for example, heavy vehicles clustered in rural areas and these areas had deadlier accidents due to a prevalence of undivided highways or a sparseness of hospitals. At this point there are too many regressors to reliably estimate a probit model, and for many cities the city fixed effect perfectly predicts the fatality indicator, forcing the city to be dropped. We thus estimate only linear probability models in columns (7) through (9) of Table 2. The addition of city fixed effects has little impact on the coefficient on striking vehicle weight, changing it from 0.10 percentage points to 0.11 percentage points $(t=18.3)$. This coefficient represents a $47 \%$ increase over the average probability of a fatality in a struck vehicle in this sample. Column (8) estimates the same specification as column (7) but limits the sample to observations for which we have data on the number of occupants per vehicle and the seat belt usage of each occupant (two controls we add in the next column). This restriction shrinks the sample in half and reduces the coefficient on striking vehicle weight to 0.07 percentage points $(t=10.8)$. However, the ratio of the coefficient to the average fatality rate in the sample remains stable (49\%). The change in the coefficient simply reflects the fact that the restricted sample contains states with a lower threshold for reporting accidents, and thus a lower fatality rate per reported accident. Column (9) adds controls for the number of occupants per vehicle and seat belt usage rate of these occupants. The coefficient on striking vehicle weight is unchanged from column (8).

The results in Table 2 suggest that selection bias has little impact on the striking vehicle weight coefficient but may affect the struck vehicle weight coefficient. In particular, the addition of driver characteristic controls in columns (5) and (6) has a notable impact on the struck vehicle weight coefficient but almost no impact on the striking vehicle weight coefficient. When adding covariates one at a time, we find that virtually all of the change in the struck vehicle weight coefficient between columns (4) and (6) can be attributed to the addition of the controls for driver age. The patterns strongly suggest that older drivers tend 
to drive heavier vehicles and that older drivers are more susceptible to dying in crashes. Since there is little correlation between the age of the struck vehicle's driver and the weight of the striking vehicle, however, the addition of driver age controls has no impact on the striking vehicle weight coefficient. Stated simply, heavy vehicles do not "seek out" elderly drivers to crash into.

The results in Table 2 also suggest that the external risk posed by light trucks is not due solely to their heavy weight. The coefficient on the indicator for whether the striking vehicle is a light truck is positive and statistically significant in every column. In our preferred specification, column (7), the coefficient implies that being struck by a light truck increases the probability of a fatality by 0.09 percentage points $(t=10.3)$, even after conditioning on striking vehicle weight. This represents a $40 \%$ increase over the average fatality rate in the sample. In comparison, if we do not control for vehicle weight, then the light truck coefficient doubles to 0.18 percentage points (i.e., 0.0018). ${ }^{17}$ The additional risk posed by light trucks may be due to the stiffness of their frames or their height incompatibility with other vehicles (Hakim 2003). However, the robustness tests that we perform in Section 5 for the vehicle weight coefficient do not apply to the light truck coefficient. Thus we cannot rule out the possibility that a portion of the light truck coefficient may represent driver selection effects - i.e., consumers that purchase light trucks may drive in an aggressive manner that generates particularly severe collisions. For this reason we do not incorporate the light truck coefficient when calculating the total externality across all vehicles in Section 6. If we were to incorporate the light truck coefficient, the total externality would be even larger. In the context of CAFE standards, however, we do consider the potential risks that light trucks pose

Table 3 presents results from estimating versions of equations (2) and (3) in which the dependent variable is the presence of serious injuries in the struck vehicle. The regressions are analogous to those in Table 2, but the dependent variable has changed from any fatalities to any serious injuries. The striking vehicle weight coefficients (or marginal effects, in the case of probit regressions) in Table 3 are approximately 6 times larger than the corresponding coefficients in Table 2. This difference arises because the probability of a

17 The 0.18 percentage point coefficient represents $77 \%$ of the average fatality rate in the sample. This effect is roughly similar in magnitude to the external effects of light trucks in two-vehicle collisions that White (2004) and Anderson (2008) estimate. Anderson (2008), for example, estimates that light trucks increase the probability of a fatality in the struck vehicle by approximately $60 \%$ of the sample average fatality rate. 
serious injury in this sample is approximately 15 times higher than the probability of a fatality. In the preferred specification, column (7), a 1,000 pound increase in striking vehicle weight raises the probability of serious injuries in the struck vehicle by 0.7 percentage points $(t=32.7)$. This figure represents $20 \%$ of the average probability of a serious injury in this sample.

Overall, the pattern of coefficients in Table 3 is similar to the pattern of coefficients in Table 2, with one exception. When the dependent variable is the presence of serious injuries (Table 3), the magnitude of the struck vehicle weight coefficient is larger than the magnitude of the striking vehicle weight coefficient. For example, in the preferred specification the striking vehicle weight coefficient is 0.7 percentage points, while the struck vehicle weight coefficient is -0.9 percentage points. This contrasts with Table 2 , in which the magnitude of the struck vehicle weight coefficient is generally smaller than the magnitude of the striking vehicle weight coefficient. Since the proportion of serious injuries that represent external costs is ambiguous, we focus on fatalities for the remainder of the paper.

Table 4 presents results testing for heterogeneity in the effect of striking vehicle weight on fatalities. In column (1), we add a quadratic term in striking vehicle weight. The coefficient on the quadratic term is zero, suggesting that the relationship between striking vehicle weight and fatalities is approximately linear. Column (2) adds an interaction between striking vehicle weight and struck vehicle weight. The average effect of striking vehicle weight (calculated across all observations) is unchanged, but the interaction term is negative and statistically significant, suggesting that striking vehicle weight has a smaller absolute impact (but similar percentage impact) when the struck vehicle is heavier. ${ }^{18}$ Nevertheless, Figure 2 demonstrates that the marginal effect of weight remains constant across the range of striking vehicle weights. Figure 2 plots the estimated marginal effects of striking vehicle weight for six models: linear OLS, quadratic OLS, quadratic OLS with an interaction term, linear probit, quadratic probit, and quadratic probit with an interaction term. ${ }^{19}$ The marginal effects of all three OLS models - linear OLS, quadratic OLS, and quadratic OLS with an interaction term - are virtually identical across the range of striking vehicle weights. Given

\footnotetext{
${ }^{18}$ Struck vehicle weight is normalized to have a mean of zero in the interaction term. The interaction effect is thus equal to zero when the struck vehicle is of average weight.

19 The "linear probit" is a model in which there are no higher order terms of striking vehicle weight. It is not literally a linear model. The "quadratic probit" is a model in which both striking vehicle weight and the square of striking vehicle weight appear on the right-hand side, and the "quadratic probit with an interaction" adds the interaction between striking vehicle weight and struck vehicle weight.
} 
the significant interaction term in Table 4, this trend suggests that the weight of the struck vehicle is not strongly correlated with the weight of the striking vehicle.

Columns (3) and (4) replicate columns (1) and (2) but are estimated using the probit model instead of the LPM. When using the probit model, the quadratic weight term is highly significant, suggesting non-linear effects from striking vehicle weight. In fact, the opposite is true. The probit is an inherently non-linear model that forces the marginal effect of vehicle weight to increase in accidents that involve heavier striking vehicles. ${ }^{20}$ Including the quadratic weight term allows the regression to offset this increase, and the resulting function is much closer to a linear function. Figure 2 demonstrates this fact. The marginal effects of the quadratic probit, the quadratic probit with an interaction term, and all of the OLS models are roughly similar, particularly between 2,400 to 4,500 pounds of vehicle weight (a range which includes over $80 \%$ of the vehicles in our sample). In contrast, the marginal effects of the linear probit model diverge substantially from the marginal effects of the other five models. Since both the flexible OLS and flexible probit models suggest that the true CEF is approximately linear in striking vehicle weight, and because the probit cannot accommodate city level fixed effects, we focus on linear probability models in much of the remaining analysis. ${ }^{21}$

Though $90 \%$ of multivehicle collisions involve two vehicles, nine percent involve three vehicles, and one percent involve four or more vehicles. Adding 1,000 pounds to a vehicle in a three-vehicle collision should increase the risk of a fatality in the other two vehicles by less than $47 \%$ each (our preferred estimate from the two-vehicle collision data set). This attenuation occurs because the extra mass of the first vehicle is now distributed across two other vehicles rather than one other vehicle. We estimate the relationship between vehicle weight and fatalities in three-vehicle collisions in Table 5. For expositional purposes, assume that Vehicle 1 is the struck vehicle and that Vehicles 2 and 3 are the striking vehicles. In Table 5, the striking vehicle weight coefficient represents the average

\footnotetext{
20 The probit marginal effect equals $\phi(X \beta) \cdot \beta$, where $\phi(\cdot)$ represents the standard normal density function. Since the probability of a fatality is less than $50 \%, \phi(X \beta)$ is increasing in $X \beta$. The marginal effect of striking vehicle weight thus increases in striking vehicle weight. The rate of increase is substantial since the effect of striking vehicle weight is large.

${ }^{21}$ For simplicity, we assume a linear effect of striking vehicle weight when comparing a gasoline tax to a weight varying mileage tax in Section 6. This assumption is conservative in that the fit between the gasoline tax and the weight varying mileage tax improves if the true marginal effects decrease for vehicles below 2,400 lbs and above 4,500 lbs, as suggested by the quadratic probit or the quadratic probit with an interaction term.
} 
effect of a 1,000 pound increase in the weight of either Vehicle 2 or 3 (but not both) on the probability of a fatality in Vehicle 1. The striking vehicle weight coefficient is positive and statistically significant in all specifications, and the magnitude of the coefficient ranges from $28 \%$ to $42 \%$ of the average probability of a fatality. Our preferred estimate, column (7), implies that a 1,000 pound increase in one vehicle raises the probability of a fatality in either of the other two vehicles by $35 \%$.

\section{Falsification Tests and Alternative Sources of IDENTIfication}

The results in Section 4 demonstrate a strong relationship between striking vehicle weight and struck vehicle fatalities. The robustness of this relationship to the inclusion of a rich set of accident and driver characteristics, as well as very fine geographic fixed effects, suggests that the striking vehicle weight coefficients represent causal effects of weight on fatality risk. However, two potential sources of upward bias seem particularly plausible. First, driver selection may bias the coefficient estimates if heavier vehicles attract aggressive drivers who get into deadlier accidents. Note, however, that only selection of drivers who get into deadlier accidents, rather than drivers who get into more accidents, could bias our estimates. ${ }^{22}$ Second, the sampling frame might bias the coefficient estimates if minor collisions involving heavier vehicles are less likely to be reported to the police, all other factors held constant. ${ }^{23}$ To test whether either of these factors could bias our results, we conduct three exercises. First, we implement a series of falsification tests that we benchmark against engineering safety estimates. Second, we estimate the effect of striking vehicle weight on fatalities using within-model changes in vehicle weight that occur when models are refreshed. Finally, we estimate the effect of striking vehicle weight on fatalities using striking vehicle occupants as an instrument for weight.

\footnotetext{
22 Because our estimates are conditional on a collision occurring, only specific types of driver selection can generate bias. Selection of "careless" drivers who simply get into more accidents of the same expected severity would not bias our results. It would increase the number of times we observe these drivers in the sample, but it would not increase the probability that someone dies in a collision conditional on the collision occurring. Selection of "aggressive" drivers who get into more severe accidents could bias our results, however. These drivers could increase the probability that someone dies in a collision conditional on the collision occurring. ${ }^{23}$ Note that, unlike the struck vehicle weight coefficients, striking vehicle weight coefficients are unlikely to be biased by any correlation between vehicle weight and vehicle safety features. It is plausible that heavier vehicles may be more or less likely to have safety features such as airbags, side impact protection beams, and unibody construction. However, these safety features are much more helpful to the striking vehicle's own occupants than they are to the occupants of other vehicles that the striking vehicle hits.
} 


\subsection{FALsification Tests}

Suppose that heavier vehicles pose no additional risk to other vehicles than lighter vehicles do, and that the estimates reported in Section 4 simply reflect the possibility that drivers of heavier vehicles are more aggressive (regardless of vehicle weight) or that heavier vehicles are less likely to generate police reports. In that case, there should be a strong positive correlation between vehicle weight and fatalities or injuries when analyzing twovehicle collisions between vehicles of the same weight. These accidents therefore provide an opportunity to test whether driver selection bias or sampling frame bias are generating our results.

It is possible, however, that heavier vehicles are safer than lighter vehicles. In that case, a positive driver selection effect might be mitigated by a negative weight effect. Put simply, even if drivers of heavier vehicles drive aggressively, our falsification test might generate a small coefficient because the heavier vehicles are fundamentally safer. We therefore benchmark the results of our falsification tests against the results of NHTSA crash tests. NHTSA crash tests entail colliding a vehicle with a concrete barrier; they are meant to simulate the results of a collision with a stationary object or a head-on collision with another vehicle of similar weight. The primary outcome in the NHTSA crash test is the Head Injury Criterion (HIC). This variable is derived from an accelerometer mounted on the crash test dummy's head and measures the forces that the head is exposed to. A higher HIC value corresponds to a higher probability of severe or fatal head injury.

Table 6 presents results from regressions of HIC scores on vehicle weight using the NHTSA crash test data. All regressions include as controls a light truck indicator, a quadratic in vehicle model year, and a quadratic in collision speed. The estimation sample in the first two columns contains all NHTSA vehicle-to-barrier frontal crash tests conducted from 1980 to 2009 (the average year is 1997). Column (1) reports regression results when the dependent variable is HIC. The results indicate that an additional 1,000 pounds of vehicle weight is associated with a statistically insignificant 3\% increase in HIC (17.7 points). Column (2) reports regression results when the dependent variable is an indicator for whether HIC exceeds 700. This threshold is of interest because it represents the point at which there is a significant (5\%) chance of severe brain injury (Mertz, Prasad, and Irwin 1997). The results 
indicate that an additional 1,000 pounds of vehicle weight is associated with a statistically insignificant $8.7 \%$ increase in the probability that HIC exceeds 700 (2.4 percentage points). The composition of vehicles that NHTSA tests, however, is not identical to the composition of vehicles on the roadways. To account for this fact, we estimate regressions in which each test result is weighted by the sales share of the tested vehicle. ${ }^{24}$ Columns (3) and (4) report the results from these regressions. The sample size falls because we do not have sales share data for every tested vehicle, but the results are qualitatively unchanged. An additional 1,000 pounds of vehicle weight is associated with small, statistically insignificant increases in HIC or the probability that HIC exceeds 700. Overall, there is a weak positive relationship between vehicle weight and HIC values. The point estimates suggest that an additional 1,000 pounds of vehicle weight could raise the fatality rate by $3 \%$ to $9 \%$, but none of the coefficients are statistically significant. We thus expect a weak relationship between vehicle weight and fatalities in collisions between two equal weight vehicles if our research design is sound.

Table 7 presents results from regressions in which the estimation sample consists of collisions involving two vehicles of similar weight - the difference in vehicle weight cannot exceed 200 pounds. In each regression, an indicator for fatalities in the struck vehicle is regressed on the average weight of the two vehicles and the set of controls from our preferred specification. Column (1) indicates that an increase of 1,000 pounds in average vehicle weight predicts a statistically insignificant $2 \%$ decrease in the probability of a fatality (0.00 percentage points). Column (2) restricts the sample to head-on collisions between two vehicles of the same weight, the type of collision simulated by NHTSA. In this sample, an increase of 1,000 pounds in average vehicle weight predicts a statistically insignificant 19\% decrease in the probability of a fatality (0.11 percentage points). ${ }^{25}$ Columns (3) and (4) replicate columns (1) and (2) but restrict the sample so that the difference in vehicle weight cannot exceed 100 pounds. The estimates remain small or negative and statistically insignificant, but are less precisely estimated.

Overall, the estimates in Table 7 indicate that there is a weak relationship between vehicle weight and fatalities in collisions between two vehicles of equal weight, and we

\footnotetext{
24 Vehicle sales share data come from Ward's Automotive Yearbook.

25 The average probability of a fatality is much higher in column (2) than in column (1) because head-on collisions are more dangerous than the average collision.
} 
cannot reject the hypothesis that this relationship is zero. This finding is consistent with NHTSA crash test results (Table 6) and inconsistent with the hypothesis that driver selection bias or sampling frame bias is generating the results in Section 4. The most precise estimate in Table 7 - column (1) - suggests that increasing average vehicle weight by 1,000 pounds decreases the fatality rate by $2 \%$. This figure is close to the range implied by the NHTSA crash test data. In contrast, if the relationship between striking vehicle weight and struck vehicle fatalities were generated by driver selection bias or sampling frame bias, then we would expect a large positive coefficient on average vehicle weight when two vehicles of equal weight collide. The preferred estimate from Section 4 indicates that a 1,000 pound increase in striking vehicle weight raises the probability of a fatality in the struck vehicle by $47 \%$. If this coefficient represented driver selection bias, and if two aggressive drivers were twice as dangerous as one aggressive driver, then we might expect a 1,000 pound increase in both vehicles weights to raise the probability of a fatality by $94 \%(2 * 47=94)$. However, no coefficient in Table 7 is above $2 \%$.

As an additional set of falsification tests, we examine the relationship between vehicle weight and fatalities in collisions involving a single vehicle. If drivers of heavier vehicles are more aggressive, then we expect a strong positive relationship between vehicle weight and fatalities in these collisions. Table 8 presents results for single-vehicle collisions. In these collisions, we regress a fatality indicator on vehicle weight and other controls. The results in column (1) pertain to all single-vehicle collisions; a 1,000 pound increase in vehicle weight is associated with a $3 \%$ increase in the probability of a fatality ( 0.04 percentage points). ${ }^{26}$ Column (2) pertains to single-vehicle frontal collisions, the type of collision simulated by NHTSA. A 1,000 pound increase in vehicle weight is associated with a $2 \%$ increase in the probability of a fatality (0.03 percentage points). Columns (3) and (4) present results that are analogous to columns (1) and (2) but are estimated using a probit specification instead of a linear probability model. In both columns, a 1,000 pound increase in vehicle weight is associated with an increase of less than 1\% in the probability of a fatality. In all columns, the percentage effects fall close to the range implied by the NHTSA crash test data, suggesting no substantial bias due to driver selection.

26 The raw magnitude of the coefficients is much larger in Table 8 than in Table 7 because the fatality rate in single-vehicle collisions is approximately 7 times higher than the fatality rate in two-vehicle collisions. This occurs because observed single-vehicle collisions tend to be more severe; drivers have no incentive to report minor single-vehicle collisions to their insurers or the police. 


\subsection{VEHICLE MODEL FiXed EFFECTS RESUlts}

To further establish the robustness of our results, we explore two alternative sources of identification. Our first alternative leverages within-model changes in vehicle weight to estimate the effect of striking vehicle weight on fatalities. To implement this design, we include vehicle model fixed effects for the striking vehicle in our preferred specification. The effect of striking vehicle weight on fatalities is thus identified on the basis of changes in vehicle weight that occur when a vehicle model is refreshed. This design minimizes the impact of driver selection as long as the composition of customers for a particular vehicle model remains relatively stable when the model is refreshed.

Table 9 reports estimates from models that include vehicle model fixed effects. Column (1) presents results from our preferred specification estimated on the sample for which we have complete vehicle model data. The sample size is substantially smaller than our main analytic sample because only four states - Kentucky, Maryland, Ohio, and Wyoming - report detailed vehicle model data. In this subsample, a 1,000 pound increase in striking vehicle weight is associated with a $47 \%$ increase in the probability of a fatality in the struck vehicle (0.06 percentage points, $t=7.3)$. This effect is consistent with the estimates from Section 4. Column (2) presents results from the same specification with vehicle model fixed effects added. ${ }^{27}$ A 1,000 pound increase in striking vehicle weight is now associated with a $58 \%$ increase in the probability of a fatality in the struck vehicle $(0.07$ percentage points, $t=4.5$ ). The correspondence between the two coefficient estimates suggests that driver selection does not seriously bias our results, and we cannot reject the hypothesis that both coefficients converge to the same value.

\subsection{INSTRUMENTAL VARIABLES RESULTS}

Our second alternate source of identification leverages the number of occupants in the striking vehicle as an instrument for striking vehicle weight. The number of occupants in the striking vehicle directly affects total striking vehicle weight, so the first condition for an

\footnotetext{
27 Across the four states with detailed vehicle model data, there are 18,746 make-model combinations. Our specification thus includes 18,745 vehicle model fixed effects.
} 
instrumental variable - that it be correlated with the regressor of interest - is satisfied. The instrumental variables (IV) regression we estimate is:

struck veh fatality $_{i}=\alpha_{1}$ striking veh added weight ${ }_{i}+\alpha_{2}$ striking veh curb weight $_{i}+$

$$
\mathrm{X}_{1 i} \gamma_{1}+\mathrm{X}_{2 i} \gamma_{2}+W_{i} \gamma_{3}+\varepsilon_{i}
$$

In this regression, striking veh added weight ${ }_{i}$ equals the number of occupants in the striking vehicle multiplied by 164 pounds, which is the average weight of an additional occupant circa $2000{ }^{28}$ The regression controls for the curb weight of each vehicle (i.e., vehicle weight absent any passengers or cargo) as well as all the covariates from our preferred specification. The identification thus comes from variation in the number of occupants in the striking vehicle after controlling for the curb weight of the striking vehicle. This means that the identifying variation in the IV regression is orthogonal to the variation in curb weight that we use in Section 4.

Nevertheless, it is not obvious that the number of occupants in the striking vehicle satisfies the second condition for an instrumental variable - that it be uncorrelated with any other factors that affect fatalities in the struck vehicle. It is possible that, even after controlling for vehicle curb weight and other characteristics, drivers who carry additional occupants in their vehicles drive more aggressively than drivers who do not carry additional occupants. If this were true, then our IV estimates would be biased upward. We thus do not interpret our IV estimates as being more robust than our OLS estimates. Instead, we recognize that the identifying variation in the IV regression is orthogonal to the identifying variation in the OLS regression. If the two regressions produce similar estimates, this suggests that both are estimating causal effects. If the two regressions produce very different estimates, this suggests that one (or both) may be biased.

\footnotetext{
28 We calculate this figure as follows. First, for the subset of accidents for which we have detailed occupant characteristics, we tabulate the share of additional occupants that are male adults, female adults, male children, and female children. We find that $21.6 \%$ of additional occupants are male adults, $39.2 \%$ are female adults, $19.2 \%$ are male children, and $20.0 \%$ are female children. Using national statistics on body weight by gender and age we then compute the average weight of an additional occupant as $0.216 * 190 \mathrm{lbs}+0.392 * 163 \mathrm{lbs}+$ $0.192 * 110 \mathrm{lbs}+0.200 * 114 \mathrm{lbs}=149 \mathrm{lbs}$ (Ogden et al. 2004). Finally, we add $15 \mathrm{lbs}$ per occupant to account for clothing, outerwear, and personal belongings (149 lbs $+15 \mathrm{lbs}=164 \mathrm{lbs})$.
} 
The last two columns of Table 9 report coefficients from the instrumental variables sample. The IV sample is approximately half the size of our main analytic sample because data on the number of occupants is not available in every state. Column (3) presents results from estimating the preferred OLS specification (column (7) of Table 2) on the IV sample. A 1,000 pound increase in striking vehicle weight is associated with a statistically significant 0.064 percentage point increase in the probability of a fatality in the struck vehicle $(t=10.7)$. This coefficient represents a $48 \%$ increase over the average probability of a fatality in a struck vehicle, which is consistent with the results in Section 4. Column (4) presents results from the IV regression in equation (4). The reported coefficient is $\alpha_{1}$, the coefficient on predicted additional weight in the striking vehicle. An additional 1,000 pounds of occupant weight in the striking vehicle is associated with a statistically significant 0.062 percentage point increase in the probability of a fatality in the struck vehicle $(t=2.4)$. This coefficient represents a $46 \%$ increase over the average probability of a fatality in the struck vehicle and is almost identical to the coefficient in column (3). The correspondence between the OLS and IV results thus increases our confidence in both estimators.

\section{Policy Implications}

The econometric evidence demonstrates that the impact of heavier striking vehicles on fatalities in struck vehicles is statistically significant and robust to the inclusion of an extensive set of vehicle, driver and accident covariates, estimation methods and identification strategies. Our estimates also scale to the national level. In a previous working paper, we estimated the same models using data from the NHTSA General Estimates System (GES). The GES is a random subsample of police reported accidents in all states. It thus has fewer observations, but greater geographic coverage, than our merged state data sets. If we estimate our preferred specification using GES data, we find that 1,000 pounds of additional vehicle weight increases the probability of a fatality by $40 \%$ in the other vehicle. This estimate is statistically significant $(t=4.8)$ and similar in magnitude to our preferred estimate of $47 \%$ from the state data sets. We cannot reject the hypothesis that both estimates converge to the same value.

We now explore whether the estimated causal effect of vehicle weight on fatalities is economically significant and compare two possible price based policies to distribute the 
external costs across drivers. To quantify the magnitude of the external costs of increased vehicle weight, we design the following counterfactual experiment. We consider the externality at the individual level, whereby purchasing and driving a heavy vehicle increases the probability of a fatality in a collision with other vehicles on the road. We conduct a thought experiment in which an individual chooses a vehicle of a certain weight; we then calculate the external costs from this individual's vehicle choice. We carry out this calculation for each driver on the road while holding the remainder of the fleet constant. We sum across individuals to get the total externality from all individuals' vehicle choices.

For the purposes of this calculation, we assume that the individual chooses a vehicle weighing as much as the average 2005 model year vehicle in our data (3,616 pounds). ${ }^{29} \mathrm{We}$ calculate total external costs against two baseline vehicles that the individual could buy - a slightly lighter vehicle and the lightest possible vehicle. The "slightly lighter" counterfactual vehicle is a proxy for the average 1989 model year vehicle in our data, which weighs 2,953 pounds. The "lightest possible" counterfactual vehicle is the smallest drivable car in mass production in 2005 , which weighs 1,850 pounds. In addition, we run a scenario that incorporates the external costs from pedestrian and motorcycle fatalities. All of our scenarios represent partial equilibrium approaches to arriving at total external costs - they assume that our regression estimates would not change if the vehicle fleet changed in response to the policies considered (in reality, there could be a modest change in the regression coefficients if the vehicle fleet changes in response to policy). Constructing a general equilibrium model is beyond the scope of this paper, and we restrict ourselves to providing estimates of the total external costs in the context of the current vehicle fleet.

We assume the individual purchases a vehicle weighing 3,616 lbs, or the mean weight of 2005 model year vehicles in our sample. The first counterfactual vehicle that the individual could have purchased weighs 2,953 pounds, or the mean weight of 1989 model year vehicles in our sample. From 1989 to 2005, the average model sold gained 625 pounds, with heterogeneity in weight gain by model. During this period the Honda Civic gained 457 pounds, the Toyota Camry gained 515 pounds, and the Ford Explorer gained 490 pounds. The Honda Odyssey, a premier minivan, gained 1,060 pounds. Honda's smallest compact

\footnotetext{
${ }^{29}$ We calculate the average weight across all 2005 (or 1989) model year cars and light trucks weighing less than $6,000 \mathrm{lbs}$ in our eight state accident database.
} 
car, the 2010 Honda Fit, weighs 360 pounds more than the 1981 Accord, which is now a full size sedan. Similar patterns emerge for most other manufacturers.

When summed across all individuals, our counterfactual scenario computes the total external cost of a 2005 model year vehicle fleet over the representative 1989 model year vehicle. Our experiment is not affected by the specific distribution of vehicle weight within the fleet as the probability of a fatality is assumed linear in striking vehicle weight - the linearity ensures that mean vehicle weight is a sufficient statistic for our policy analysis. We choose 2005 as our cutoff year as many of the parameters necessary for our full simulation were only available until 2005.

The change in the probability of an external fatality for an individual buying vehicle model $i$ weighing $w_{i}$ over a lighter vehicle weighing $w_{c f}$ is given by:

$$
\text { External } \operatorname{Cost}_{i}=\beta \cdot\left(w_{i}-w_{c f}\right) \cdot P(\text { accident }) \cdot V S L
$$

For $\beta$ we employ our preferred estimate of the causal effect of weight on the probability of a fatality in an accident, or 0.110 percentage points for each additional 1,000 lbs in striking vehicle weight. ${ }^{30}$ In all experiments, we set $w_{i}$ at 3,616 pounds. We calculate the probability of a vehicle being involved in a multivehicle collision at 3.65\% per year (NHTSA, 2007). ${ }^{31}$ We apply the DOT value of a statistical life of $\$ 5.8$ million.

If our simulated individual chooses a vehicle weighing 3,616 lbs $\left(w_{i}\right)$ instead of one weighing 2,953 lbs $\left(w_{c}\right)$, she causes an additional 0.000027 external fatalities per year in expectation, valued at $\$ 154.39$. Summing this figure across all vehicles, the total external cost of vehicle weight gain relative to the 1989 baseline vehicle is $\$ 35$ billion per year. This figure represents the "weight gain since 1989" scenario but does not encompass the total external costs of vehicle weight.

Our second counterfactual scenario assumes the individual purchases the 3,616 lb vehicle $\left(w_{i}\right)$ over a vehicle weighing $1,850 \mathrm{lbs}\left(w_{c}\right)$, which represents the lightest vehicle in mass production that can transport at least two adult passengers and is classified as an automobile. This is the approximate weight of Toyota's iQ, Mercedes Benz's Smart Car, or the first generation Honda Insight. The intuition behind calculating the total external cost using this baseline vehicle is that individuals privately choose the size of the externality by

${ }^{30}$ For comparison, the probability in our sample of a fatality in a two-vehicle collision (conditional on the collision occurring) is $0.190 \%$.

31 We estimate the probability of being involved in an accident by dividing the total number of vehicles involved in multivehicle collisions by the total number of registered vehicles in 2005 (BTS, 2010 Table 1-11). 
choosing a heavier vehicle than required to provide baseline transportation services. This calculation recognizes that a driver of a Smart Car poses little or no risk to other roadway users except bicyclists or motorcyclists. ${ }^{32}$

If our simulated individual chooses a vehicle weighing 3,616 lbs instead of one weighing 1,850 lbs, she causes an additional 0.000071 external fatalities per year in expectation, valued at $\$ 411.34$. Summing across all drivers, this translates into a total external cost of $\$ 93$ billion per year. This scenario, however, ignores the external fatality risks that vehicles pose to pedestrians and motorcyclists. In 2005, there were 2,659 motorcycle crash fatalities (involving light vehicles) and 5,864 non-motorist fatalities due to fatal crashes (NHTSA 2010). This is equivalent to an external "baseline" fatality cost of $\$ 49.4$ billion. The total external cost of "excess" vehicle weight and baseline fatality risk is therefore $\$ 142.4$ billion.

The above calculations ignore the impact of higher striking vehicle weight in multivehicle collisions with more than two vehicles. The majority of these accidents involve three vehicles. We repeat the simulation above but add the external costs in three-vehicle collisions. We assume that striking vehicle weight has half the causal effect (per vehicle struck) in three-vehicle accidents as compared to its effect in two-vehicle collisions. This assumption is conservative in comparison to our three-vehicle collision estimates in Table 5. These calculations raise external costs in the "weight gain since 1989" scenario to $\$ 38$ billion and external costs in the "lightest possible vehicle" scenario to $\$ 101.6$ billion. Total external costs rise to $\$ 151$ billion. ${ }^{33}$

While the magnitude of the total external costs is a straightforward calculation, translating it into an optimal policy is not. The externality consists of fatalities in collisions with pedestrians, motorcyclists, and other vehicles. These costs, as discussed in Section 2, are not currently reflected in liability insurance because most coverage levels are far below the VSL of $\$ 5.8$ million. One way to incorporate these external risks is to include them in a per mile insurance charge. In contrast to existing proposals for "pay as you drive" (PAYD) insurance (e.g. Parry 2005; Bordoff and Noel 2008), our results demonstrate that the per mile insurance charge should vary sharply by weight - a heavier car generates greater

\footnotetext{
32 We do not consider a "zero weight" baseline vehicle because that weight lies far outside the support of our data. Furthermore, it is unclear what counterfactual to construct if the vehicle does not exist at all. Would the collision not occur, or would the struck vehicle instead hit a different vehicle or a roadside object?

33 A spreadsheet detailing these calculations is available from the authors.
} 
expected per mile external costs than a lighter car. In order to assess a tax that varies per pound and per mile, one needs accurate information on vehicle miles travelled (VMT) for each vehicle, which creates substantial monitoring challenges.

A practical policy alternative is to distribute the total external costs by raising the gasoline tax assessed per gallon. Taxing gasoline is appealing because it is simple and because gasoline usage is positively related to both miles driven and vehicle weight. The United States consumed 140 billion gallons of gasoline in 2005 (EIA 2010). If we spread the total external costs calculated above across 140 billion gallons of gasoline, this translates into 27 cents per gallon in the "weight gain since 1989" scenario ( $\$ 38$ billion/140 billion gallons = 27 cents/gallon). The total externality due to vehicle fatalities when the baseline vehicle is 1,850 pounds translates into a tax of 73 cents per gallon ( $\$ 101.6$ billion/140 billion gallons $=$ 73 cents/gallon). Including pedestrian and motorcycle fatalities translates into a tax of $\$ 1.08$ per gallon ( $\$ 151$ billion $/ 140$ billion gallons $=\$ 1.08 /$ gallon $)$.

While the gasoline tax does not differ by the type of vehicle fueled, it is correlated with vehicle weight, because heavier vehicles have lower fuel economy. Figure 3 plots a lowess smoother of miles per gallon (mpg) against vehicle weight, estimated for cars in model year 2005 using the data from Knittel (forthcoming). ${ }^{34}$ There is a strong negative and slightly nonlinear relationship between the two variables. A linear regression indicates that an additional 1,000 pounds in vehicle weight decreases fuel economy by $4.5 \mathrm{mpg}$. A gas tax thus results in heavier vehicles indirectly paying a higher per mile tax through the correlation of mpg with vehicle weight. In this sense, the gas tax approximates a weight varying mileage $\operatorname{tax}$.

A natural question is how close the gasoline tax comes to achieving the desired weight varying mileage tax. We perform a back of the envelope calculation using a large set of vehicles for which we have vehicle weight and mpg ratings from Knittel (forthcoming). For the analysis, we remove boutique vehicles, which essentially have zero market share (e.g. Lamborghini, Ferrari, Bentley), flex fuel vehicles, which have inflated mpg ratings for accounting reasons, and a few miscoded observations. We examine vehicles built from 1997 to 2006 to approximate the vehicle fleet in the last year of our sample. This sample contains

\footnotetext{
${ }^{34}$ For this comparison, we require vehicle weight and EPA fuel economy ratings. The latter are not contained in our VIN decoder database, but Chris Knittel has graciously shared his model level data on weight and fuel economy ratings.
} 
8,201 model-year combinations and includes most cars and light trucks sold in the United States during this period.

The weight based external cost for vehicle type $i$ per VMT is given by

$$
c_{i}^{e}=\frac{\beta\left(w_{i}-w_{c f}\right) \cdot V S L \cdot P(\text { accident })}{V M T}+c_{\text {pedmot }}^{e}
$$

where $\beta$ is again the estimated causal effect of vehicle weight on external fatalities (0.0011), $w_{i}$ is the chosen vehicle's weight, $w_{c f}$ is the baseline vehicle's weight, VSL is the value of a statistical life and $P($ accident $)$ is the probability of being involved in a multivehicle collision. VMT are held constant for each model at 11,000 miles per year. The parameter $c_{\text {pedmot }}^{e}$ is the total number of fatalities in collisions between vehicles and pedestrians, bicyclists and motorcycles, multiplied by the VSL; it sums to $\$ 49.4$ billion, or 1.65 cents per VMT. We calculate $c_{i}^{e}$ for each model in our database. The average value of $c_{i}^{e}$ across all models is 5.4 cents per mile, and it increases by 2.1 cents per mile for every 1,000 lb increase in $w_{i}$.

The gas tax per mile for model $i$ is given by

$$
c_{i}^{g}=\frac{\bar{c}_{e}}{m p g_{i}}
$$

where $\bar{c}_{e}$ is the average per gallon external cost of fatalities in multivehicle collisions or collisions with pedestrians, bicyclists, or motorcycles. We calculate $\bar{c}_{e}$ above as $\$ 1.08$ per gallon. For $m p g_{i}$ we use the standard 45/55 weighting of the EPA city and highway fuel economy ratings. ${ }^{35}$ The gas tax per mile therefore only varies across models through differences in fuel economy.

The weight-based tax displays higher variability, with a standard deviation of 1.6 cents per mile compared to the gas tax's standard deviation of 1.3 cents per mile. The difference between the two taxes for model $i$ can be expressed as:

$$
\Delta_{i}=c_{i}^{g}-c_{i}^{e}=\alpha+\frac{\bar{c}_{e}}{m p g_{i}}-\gamma w_{i}
$$

\footnotetext{
35 Pre-2008 EPA fuel economy ratings are widely recognized to overstate the actual mileage achieved by the average driver (Edmunds 2006). This affects our subsequent analysis because the $\$ 1.08$ gas tax was derived from actual fuel economy rather than the EPA's forecast fuel economy. We thus rescale the EPA ratings so that the average fuel economy in this sample matches the average fuel economy observed nationwide (17.8 mpg), after adjusting for weight differences between the two samples. The rescaling factor that achieves this equivalence is 0.73 . Our conclusions in the subsequent analysis are unchanged if we instead leave the EPA ratings untouched and recalculate the gas tax using EPA mileage ratings - in both cases the per mile gas tax closely tracks the weight based mileage tax.
} 
where $\alpha=\frac{\beta \cdot w_{c f} \cdot V S L \cdot P(\text { accident })}{V M T}-c_{\text {pedmot }}^{e}$ and $\gamma=\frac{\beta \cdot V S L \cdot P(\text { accident })}{V M T}$. We keep both $\alpha$ and $\gamma$ fixed at the values stated previously in this simulation. From equations (6) and (7), we see that the per mile weight tax increases in weight and the gas tax per mile decreases in fuel efficiency, as expected. However, an interesting relationship emerges for the difference between the two pricing tools, given in equation (8). $\Delta_{i}$ is decreasing in better fuel efficiency and higher weight. A negative $\Delta_{i}$ means that, for vehicle model $i$, the weight tax is higher than the gas tax. Thus, cars most heavily advantaged by the gas tax are heavy vehicles that are relatively fuel efficient for their size (e.g. Mercedes E320 CDI [35.5 mpg; 3,835 lbs]). Cars most heavily advantaged by the weight tax are lighter vehicles that are gas guzzlers compared to others their size (e.g. Ford GT [18.7 mpg; 3,351 lbs]).

Figure 4 presents a scatterplot of the gas tax versus the weight tax for all models from 1997-2006 in the cleaned Knittel (forthcoming) database. The difference between the two taxes is small for most models, but it can be significant at the extremes, ranging between -3.7 cents to 5.3 cents per mile. A one cent difference per mile equates to $\$ 110$ dollars on an annual basis. For $62 \%$ of the models in our database, the absolute value of the difference between the two taxes is less than one cent per mile, and for $95 \%$ of the models the absolute value of the difference is less than 2 cents per mile. The average difference between the two taxes is 0.69 cents per mile, which represents $12.9 \%$ of the average value of the per mile weight tax.

A related question is what level of gas tax would best mimic the weight tax across all models. For any gas tax set at $\bar{c}$ per gallon, we can write the following equation:

$$
c_{i}^{e}=\bar{c} \cdot 1 / m p g_{i}+\varepsilon_{i}
$$

In this equation, $\bar{c} \cdot 1 / m p g_{i}$ equals the gas tax per mile for vehicle $i$ (dollars/gallon divided by miles $/$ gallon $=$ dollars $/$ mile), and $\varepsilon_{i}$ equals the difference between the gas tax per mile and the weight based mileage tax. If we specify a quadratic loss function, we can estimate the gas tax that best mimics the weight tax by estimating a least squares regression of the weight based mileage tax on the inverse of miles per gallon. ${ }^{36}$ Each observation in this

\footnotetext{
36 Equation (9) reveals that we must constrain the intercept to be zero in this regression - the only degree of freedom in setting the gas tax comes from choosing $\bar{c}$.
} 
regression is a different vehicle model. The resulting estimate from this OLS regression is $\bar{c}=\$ 0.96$ per gallon, which is similar in magnitude to our previously computed tax of $\$ 1.08$ (though the two quantities are significantly different at the $5 \%$ level). ${ }^{37}$ The total revenue raised by either of the gas taxes is close to the total revenue raised by the mileage based tax. In all cases, the revenues could be redistributed to make the taxes revenue neutral.

While many countries encourage fuel efficiency through high gasoline taxes, the United States encourages fuel efficiency through CAFE standards. In principle, fuel economy standards could achieve the same "downsizing" of the vehicle fleet as a gasoline tax - a properly specified fuel economy standard should act as a de facto tax on heavier vehicles. A primary difference between the two instruments is that the fuel economy standard "tax" would be collected when purchasing the vehicle and would be amortized over the vehicle's lifetime VMT, while the gas tax would be collected in small increments throughout the life of the vehicle. This difference could be important if consumers exhibit high discount rates or if salience is important (Finkelstein 2009). Calculating the exact fuel economy standards that achieve equivalent effects to a $\$ 1.08$ per gallon gas tax is beyond the scope of this paper, as it requires a variety of supply and demand elasticities. Nevertheless, we note two important points in the context of CAFE standards.

First, current CAFE standards are insufficient to internalize the externality presented in this paper. Goldberg (1998) estimates that CAFE increases the price of pickup trucks by $0.6 \%$ and reduces the price of subcompacts by $0.5 \%$. This equates to a tax on pickup trucks (relative to subcompacts) of approximately $\$ 200$. The gasoline tax discussed above, however, equates to a tax on pickup trucks (relative to subcompacts) of over $\$ 4,000$ over the life of the vehicle. Second, the light truck coefficient in Table 2 suggests that removing the current split in CAFE standards between cars and light trucks would improve welfare. The results in Table 2 imply that light truck frames impose significant external risks upon other roadway users but provide little or no safety benefit to their own occupants. This suggests that light truck purchases should be discouraged, but current CAFE standards encourage light truck production by imposing a much lower mileage standard on trucks than on cars.

\footnotetext{
37 The least squares regression minimizes the sum of squared deviations. We can alternatively estimate a median regression to minimize the sum of absolute deviations. The median regression coefficient is $\$ 0.95$, which is virtually identical to the OLS coefficient of $\$ 0.96$.
} 


\section{Conclusion}

The US vehicle fleet has become significantly heavier over the past two decades. The average car on the road in 2008 was roughly 530 pounds heavier than the average car on the road in 1988, representing a $20 \%$ increase. This trend and its potential traffic safety implications have been widely discussed by policymakers when contemplating more stringent fuel economy standards or greenhouse gas emissions standards. However, it is less widely recognized that an unregulated vehicle fleet is inefficiently heavy due to the "arms race" nature of vehicle choice. In this paper, we estimate the external effects of choosing a heavier vehicle on fatalities in two-vehicle collisions. We present robust evidence that increasing striking vehicle weight by 1,000 pounds increases the probability of a fatality in the struck vehicle by $40 \%$ to $50 \%$. This finding is unchanged across different specifications, estimation methods, and different subsets of the sample. We show that there are also significant impacts on serious injuries.

The external costs of fatalities are currently not internalized in the form of a first- or second-best policy. We calculate that a simple gasoline tax that internalizes the fleet weight gain since 1989 is 27 cents per gallon. We further calculate that internalizing the total cost of external fatalities due to vehicle weight and operation, including crashes with motorcycles and pedestrians, requires a tax on the order of $\$ 1.08$ per gallon. Parry and Small (2005), applying a lower VSL to monetize other external costs and not accounting for the vehicle weight externality, calculate an optimal value of $\$ 1.01$ per gallon for the U.S. gas tax (approximately 60 cents above its current level). Internalizing the vehicle weight externality would increase this optimal value substantially. 


\section{References}

Ahmad, S., and D. L. Greene. 2005. "Effect of Fuel Economy on Automobile Safety: A Reexamination." Journal of the Transportation Research Board (1941): 1-7.

Anderson, M. 2008. "Safety for whom? The effects of light trucks on traffic fatalities." Journal of Health Economics 27(4): 973-989.

Austin, D., and T. Dinan. 2005. "Clearing the air: The costs and consequences of higher CAFE standards and increased gasoline taxes." Journal of Environmental Economics and Management 50(3): 562-582.

Bento, A. M, L. H Goulder, M. R Jacobsen, and R. H von Haefen. 2009. "Distributional and efficiency impacts of increased US gasoline taxes." The American Economic Review 99(3): 667-699.

Bordoff, J., and P. Noel. 2008. "Pay-As-You-Drive auto insurance: A simple way to reduce driving-related harms and increase equity." Hamilton Project Discussion Paper.

Busse, M. R, C. R Knittel, and F. Zettelmeyer. 2009. "Pain at the Pump: How Gasoline Prices Affect Automobile Purchasing in New and Used Markets."

Crandall, Robert W., and John D. Graham. 1989. "The Effect of Fuel Economy Standards on Automobile Safety." Journal of Law and Economics 32(1): 97-118.

Edmunds, Dan. 2006. "EPA Overhauls Fuel Economy Estimates for 2008.” http://www.edmunds.com/fuel-economy/epa-overhauls-fuel-economy-estimatesfor-2008.html.

Evans, L. 1984. “Accident involvement rate and car size." Accident Analysis \& Prevention 16(5): 387-406.

Fernández-Val, I. 2009. "Fixed effects estimation of structural parameters and marginal effects in panel probit models." Journal of Econometrics 150(1): 71-85.

Finkelstein, Amy. 2009. "E-ZTAX: Tax Salience and Tax Rates." Quarterly Journal of Economics 124(3): 969-1010.

Gayer, T. 2004. "The Fatality Risks of Sport-Utility Vehicles, Vans, and Pickups Relative to Cars." Journal of Risk and Uncertainty 28(2): 103-133.

Goldberg, Pinelopi Koujianou. 1998. "The Effects of the Corporate Average Fuel Efficiency Standards in the US." The Journal of Industrial Economics 46(1): 1-33.

Hakim, Danny. 2003. "S.U.V.'s to Be Redesigned to Reduce Risk to Cars." The New York Times. http://www.nytimes.com/2003/12/04/business/suv-s-to-be-redesigned-toreduce-risk-to-cars.html?pagewanted $=$ all. 
"Insurance Information Institute - Compulsory Auto/Uninsured Motorists." http://www.iii.org/IU/Compulsory-Auto-Uninsured-Motorists/.

Jacobsen, M. 2010. "Fuel Economy, Car Class Mix, and Safety.” U.C. San Diego Working Paper.

Kahane, C. 2003. "Vehicle weight, fatality risk and crash compatibility of model year 1991-99 passenger cars and light trucks." NHTS A Technical Report.

Kennickell, A. B. 2003. "A Rolling Tide: Changes in the Distribution of Wealth in the US." Federal Reserve Occasional Staff Study.

Khazzoom, J. D. 1994. "Fuel Efficiency and Automobile Safety: Single-Vehicle Highway Fatalities for Passenger Cars.” The Energy Journal 15(4): 49-102.

Kleit, A. N. 2004. "Impacts of long-range increases in the corporate average fuel economy (CAFE) standard." Economic Inquiry 42(2): 279-94.

Klier, T., and J. Linn. 2008. "New Vehicle Characteristics and the Cost of the Corporate Average Fuel Economy Standard."

Knittel, C. R. Forthcoming. "Automobiles on Steroids: Product Attribute Trade-Offs and Technological Progress in the Automobile Sector.” American Economic Review.

Li, S., C. Timmins, and R. H von Haefen. 2009. "How do gasoline prices affect fleet fuel economy?” American Economic Journal: Economic Policy 1(2): 113-137.

Li, Shanjun. Forthcoming. "Traffic safety and vehicle choice: quantifying the effects of the 'arms race' on American roads." Journal of Applied Econometrics.

Mertz, H. J., P. Prasad, and A. L. Irwin. 1997. "Injury risk curves for children and adults in frontal and rear collisions (SAE 973318)." In Proceeding of the 41st Stapp Car Crash Conference, p. 13-30.

National Highway Traffic Safety Administration. "FARS Encyclopedia.” http://wwwfars.nhtsa.dot.gov/Main/index.aspx.

- 2007. "Traffic Safety Facts 2005.”

Noland, R. B. 2005. "Fuel economy and traffic fatalities: multivariate analysis of international data." Energy Policy 33(17): 2183-2190.

- 2004. "Motor Vehicle Fuel Efficiency and Traffic Fatalities." The Energy Journal 25(4): 1-22.

Ogden, Cynthia L, Cheryl D Fryar, Margaret D Carroll, and Katherine M Flegal. 2004.

"Mean body weight, height, and body mass index, United States 1960-2002." Advance Data (347): 1-17. 
Parry, Ian W. H. 2005. "Is Pay-as-You-Drive Insurance a Better Way to Reduce Gasoline than Gasoline Taxes?" The American Economic Review 95(2): 288-293.

Parry, Ian W. H., and Kenneth A. Small. 2005. "Does Britain or the United States Have the Right Gasoline Tax?” The American Economic Review 95(4): 1276-1289.

Peltzman, Sam. 1975. “The Effects of Automobile Safety Regulation.” The Journal of Political Economy 83(4): 677-725.

Portney, Paul R., Ian W. H. Parry, Howard K. Gruenspecht, and Winston Harrington. 2003. "Policy Watch: The Economics of Fuel Economy Standards." The Journal of Economic Perspectives 17(4): 203-217.

Robertson, L. S. 1991. "How to save fuel and reduce injuries in automobiles." The Journal of Trauma 31(1): 107.

United States Environmental Protection Agency. 2009. "Light-Duty Automotive Technology, Carbon Dioxide Emissions, and Fuel Economy Trends: 1975 Through 2009."

US Energy Information Administration. "Use of Gasoline - Energy Explained, Your Guide To Understanding Energy." http://tonto.eia.doe.gov/energyexplained/index.cfm?page=gasoline_use.

Van Auken, M., and J. W Zellner. 2005. "An Assessment of the Effects of Vehicle Weight and Size on Fatality Risk in 1985 to 1998 Model Year Passenger Cars and 1985 to 1997 Model Year Light Trucks and Vans.” SAE International.

Ward's Reports Incorporated. 1994. Ward's Automotive Yearbook.

White, M. J. 2004. “The 'Arms Race' on American Roads: The Effect of Sport Utility Vehicles and Pickup Trucks on Traffic Safety." The Journal of Law and Economics 47: 333-355. 
Figure 1: External Costs of Vehicle Weight

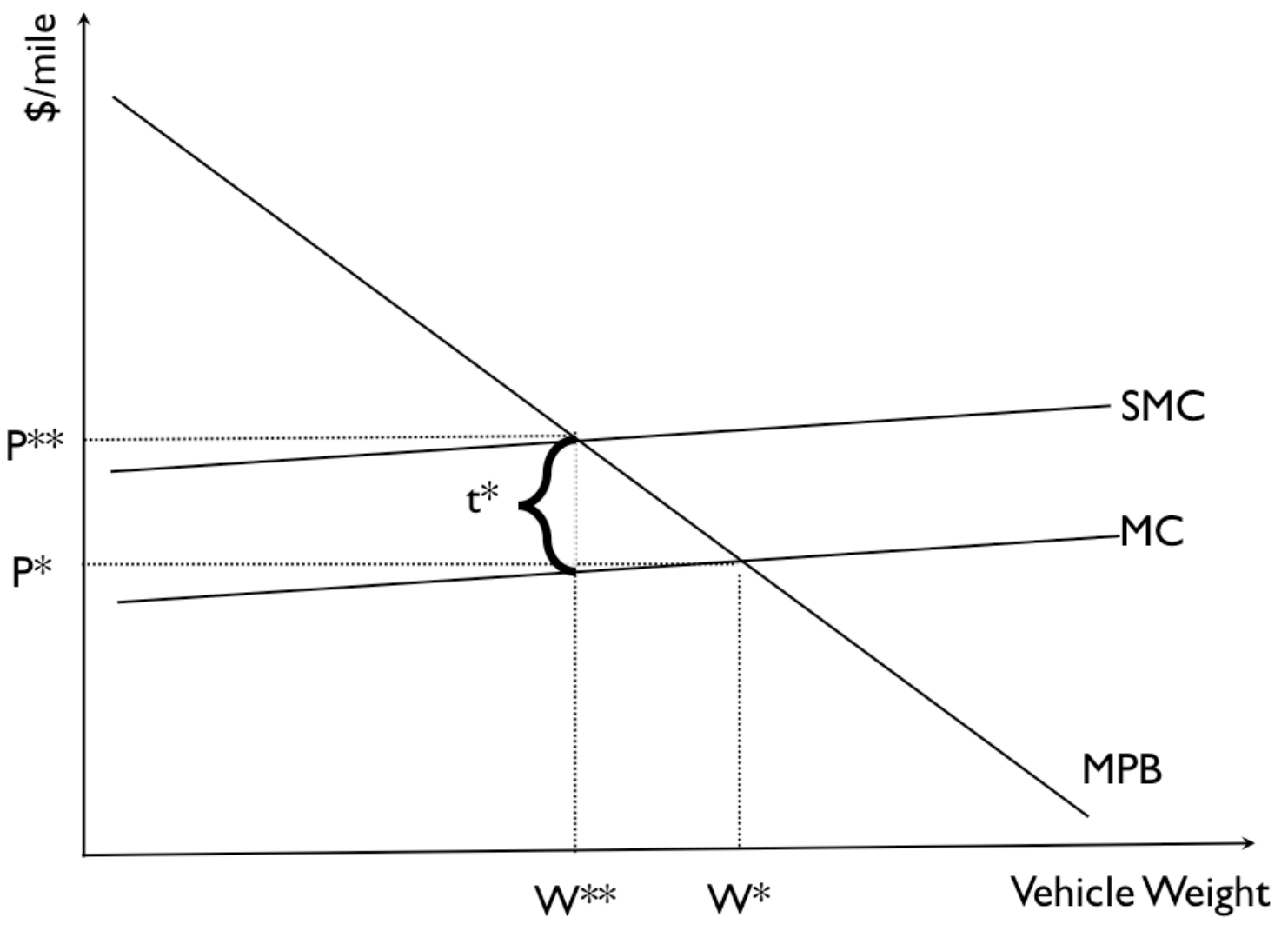


Figure 2: Marginal Effects of Striking Vehicle Weight

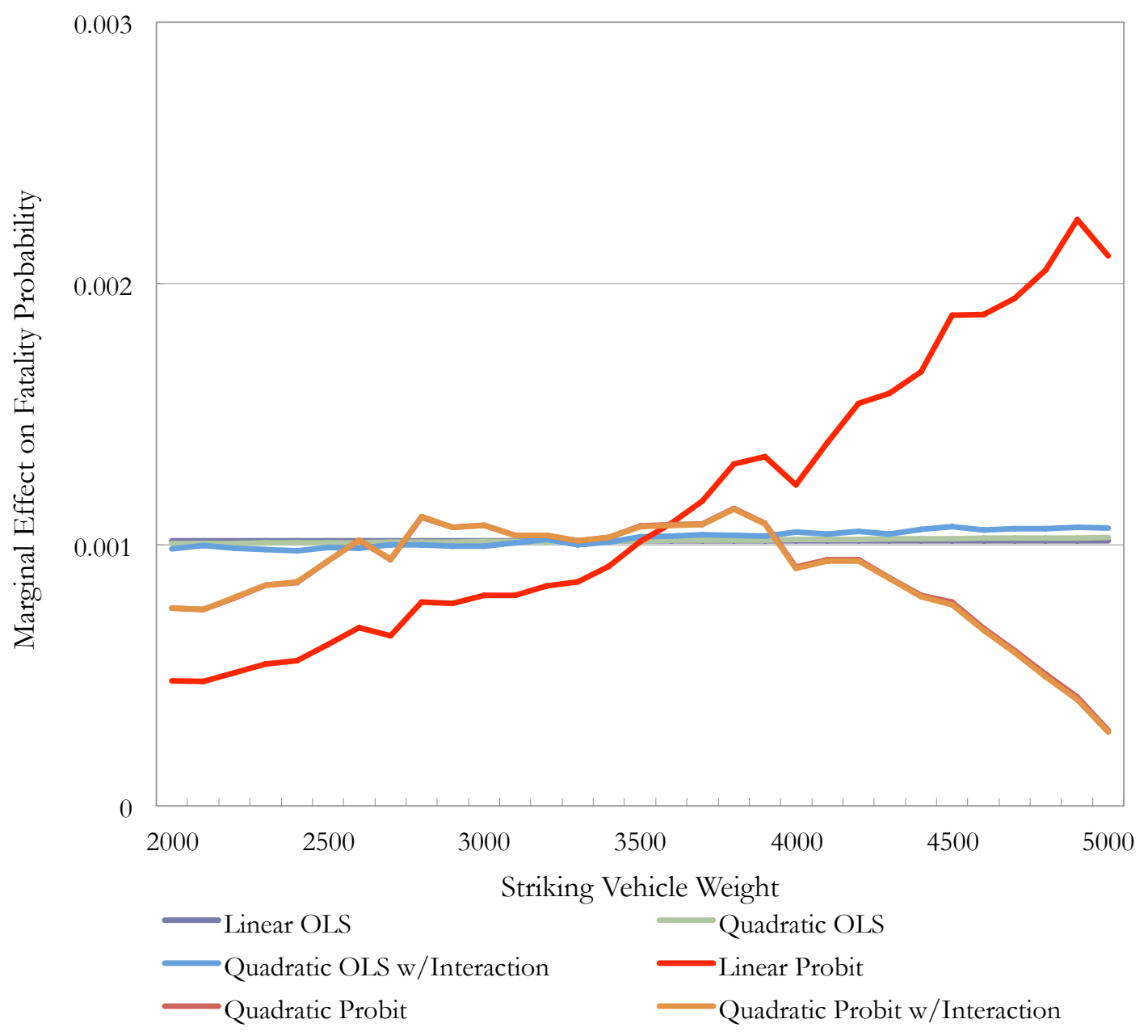


Figure 3: Fuel Economy vs. Weight for 2005 Model Year Light Vehicles

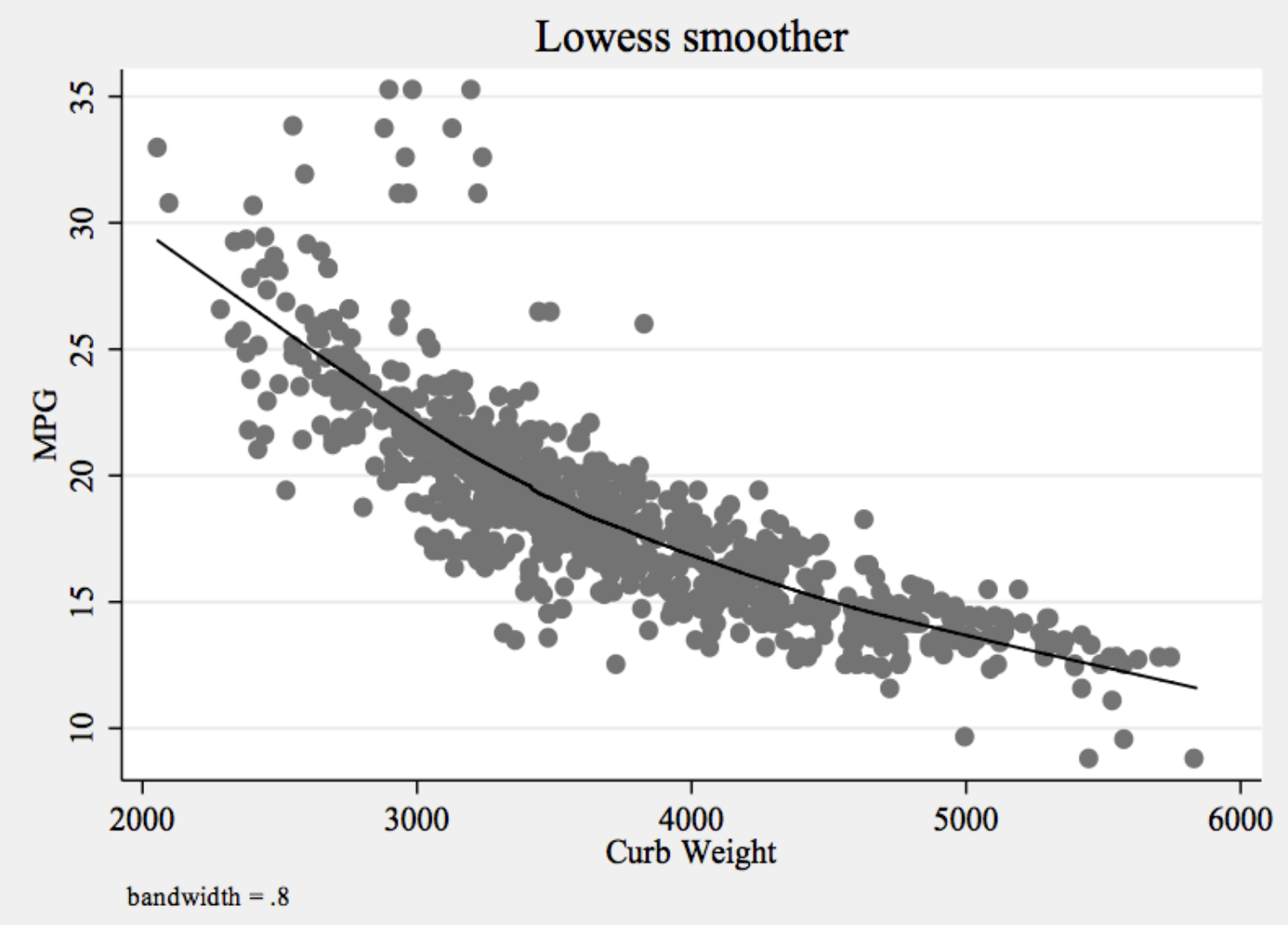


Figure 4: Sunflower Scatterplot of Gas Tax vs. Weight Tax for Cars and Trucks

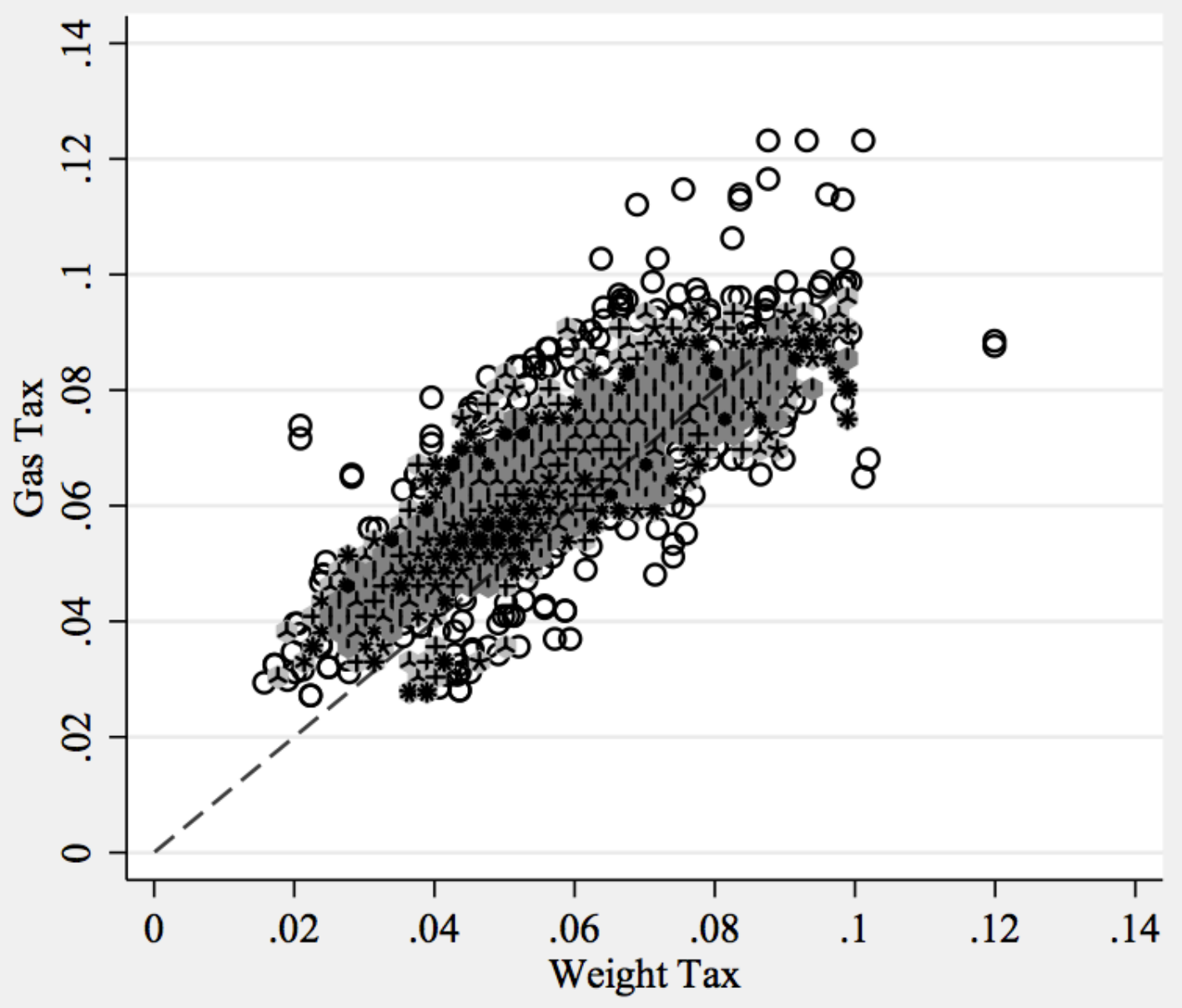

$$
\begin{array}{ll}
\text { O } & \text { Single Obs. } \\
\text { \& } 1 \text { petal }=13 \text { obs. }
\end{array}
$$

Notes: The graph above displays the joint distribution of the weight tax and gas tax per mile for the sample of cars and trucks with model years 1997-2006 from the database provided by Knittel (forthcoming). We remove boutique cars, flex fuel vehicles, and a few outliers with incorrectly recorded fuel ratings. The sunflower plot bunches multiple observations into single flowers, where the number of petals indicates the total number of observations represented by the flower. The petals of light flowers represent one observation each and the petals of darker flowers represent 13 observations each. 
Table 1: Summary Statistics for Two-Vehicle Collision Data Set

\begin{tabular}{|c|c|c|c|c|}
\hline & \multicolumn{2}{|c|}{ Base Sample } & \multicolumn{2}{|c|}{ Complete Covariates Sample } \\
\hline & $\begin{array}{c}\text { Mean } \\
\text { (Std Dev) }\end{array}$ & Sample Size & $\begin{array}{c}\text { Mean } \\
\text { (Std Dev) }\end{array}$ & Sample Size \\
\hline Weight & $\begin{array}{c}3,076 \mathrm{lbs} \\
(685)\end{array}$ & $4,849,575$ & $\begin{array}{c}3,113 \mathrm{lbs} \\
(694)\end{array}$ & $2,829,768$ \\
\hline Light Truck & $\begin{array}{c}24.5 \% \\
(43.0)\end{array}$ & $4,849,575$ & $\begin{array}{c}25.8 \% \\
(43.8)\end{array}$ & $2,829,768$ \\
\hline Model Year & $\begin{array}{l}1992 \\
(5.6)\end{array}$ & $4,849,575$ & $\begin{array}{l}1993 \\
(5.7)\end{array}$ & $2,829,768$ \\
\hline Accident Year & $\begin{array}{l}1998 \\
(4.4)\end{array}$ & $4,849,575$ & $\begin{array}{l}1999 \\
(4.3)\end{array}$ & $2,829,768$ \\
\hline Occupants & $\begin{array}{c}1.41 \\
(0.84)\end{array}$ & $2,608,821$ & $\begin{array}{c}1.45 \\
(0.87)\end{array}$ & $1,476,441$ \\
\hline Fatality & $\begin{array}{c}0.19 \% \\
(4.36)\end{array}$ & $4,849,575$ & $\begin{array}{c}0.23 \% \\
(4.83)\end{array}$ & $2,829,768$ \\
\hline Serious Injury & $\begin{array}{l}2.7 \% \\
(16.1)\end{array}$ & $4,849,575$ & $\begin{array}{l}3.4 \% \\
(18.0)\end{array}$ & $2,829,768$ \\
\hline Alcohol Involved & $\begin{array}{l}8.3 \% \\
(27.6)\end{array}$ & $2,753,533$ & $\begin{array}{l}10.0 \% \\
(30.1)\end{array}$ & $1,723,694$ \\
\hline
\end{tabular}

Notes: Both samples are limited to collisions involving two light vehicles built post-1980. The complete covariates sample is further limited to collisions in which all covariates in our preferred specification are non-missing. 
Table 2: Effect of Vehicle Weight on Fatalities

Dependent Variable: Presence of Fatalities in Struck Vehicle

(1)

(2)

(3)

(4)

(5)

(6)

(7)

(8)

(9)

Weight of Striking Vehicle (1000s of lbs)

\begin{tabular}{|c|c|c|c|c|c|c|c|c|}
\hline $\begin{array}{c}0.00088 \\
(0.00004)\end{array}$ & $\begin{array}{c}0.12685 \\
(0.00531)\end{array}$ & $\begin{array}{c}0.00093 \\
(0.00005)\end{array}$ & $\begin{array}{c}0.12797 \\
(0.00616)\end{array}$ & $\begin{array}{c}0.00101 \\
(0.00005)\end{array}$ & $\begin{array}{c}0.13440 \\
(0.00685)\end{array}$ & $\begin{array}{c}0.00110 \\
(0.00006)\end{array}$ & $\begin{array}{c}0.00065 \\
(0.00006)\end{array}$ & $\begin{array}{c}0.00064 \\
(0.00006)\end{array}$ \\
\hline 0.00088 & 0.00077 & 0.00093 & 0.00085 & 0.00101 & 0.00086 & 0.00110 & 0.00065 & 0.00064 \\
\hline $46 \%$ & $41 \%$ & $42 \%$ & $38 \%$ & $44 \%$ & $37 \%$ & $47 \%$ & $49 \%$ & $48 \%$ \\
\hline $\begin{array}{l}-0.00047 \\
(0.00004)\end{array}$ & $\begin{array}{l}-0.08196 \\
(0.00644)\end{array}$ & $\begin{array}{l}-0.00053 \\
(0.00004)\end{array}$ & $\begin{array}{l}-0.08548 \\
(0.00727)\end{array}$ & $\begin{array}{l}-0.00101 \\
(0.00005)\end{array}$ & $\begin{array}{l}-0.15988 \\
(0.00815)\end{array}$ & $\begin{array}{l}-0.00097 \\
(0.00005)\end{array}$ & $\begin{array}{l}-0.00060 \\
(0.00006)\end{array}$ & $\begin{array}{l}-0.00065 \\
(0.00006)\end{array}$ \\
\hline $\begin{array}{c}0.00117 \\
(0.00006)\end{array}$ & $\begin{array}{c}0.15977 \\
(0.00861)\end{array}$ & $\begin{array}{c}0.00105 \\
(0.00008)\end{array}$ & $\begin{array}{c}0.13016 \\
(0.00958)\end{array}$ & $\begin{array}{c}0.00088 \\
(0.00009)\end{array}$ & $\begin{array}{c}0.10113 \\
(0.01075)\end{array}$ & $\begin{array}{c}0.00093 \\
(0.00009)\end{array}$ & $\begin{array}{c}0.00054 \\
(0.00010)\end{array}$ & $\begin{array}{c}0.00054 \\
(0.00010)\end{array}$ \\
\hline $\begin{array}{l}-0.00014 \\
(0.00006)\end{array}$ & $\begin{array}{l}-0.02541 \\
(0.00987)\end{array}$ & $\begin{array}{l}-0.00036 \\
(0.00007)\end{array}$ & $\begin{array}{l}-0.06192 \\
(0.01081)\end{array}$ & $\begin{array}{l}-0.00001 \\
(0.00007)\end{array}$ & $\begin{array}{l}-0.03605 \\
(0.01154)\end{array}$ & $\begin{array}{c}0.00021 \\
(0.00008)\end{array}$ & $\begin{array}{l}-0.00015 \\
(0.00009)\end{array}$ & $\begin{array}{l}-0.00012 \\
(0.00009)\end{array}$ \\
\hline
\end{tabular}

Struck Vehicle is Light Truck

OLS

Probit

OLS

Probit

OLS Probit

OLS

OLS

OLS

Weather, Time, and County Fixed Effects

Yes

Yes

Yes

Yes

Yes

Yes

Yes

Driver Characteristics

Yes

Yes

Yes

Yes

Yes

City Fixed Effects

Occupants and Seat Belt Usage

Sample Size

Notes: Each column represents a separate regression. The estimation sample is limited to collisions involving two vehicles. Parentheses contain standard errors clustered at the

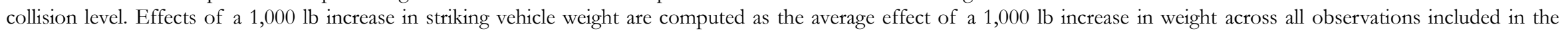
regression. All regressions include as right-hand-side variables the weight of each vehicle, indicators for whether each vehicle is a light truck, and year fixed effects. Weather, time, and county fixed effects controls include rain, darkness, day of week (weekday versus weekend), Interstate highway, a quadratic in model year for each vehicle, and year, hour, and county fixed effects. Driver characteristic controls include quadratics in driver age, indicators for drivers under 21 or over 60, indicators for male drivers and young male drivers, and indicators for any seat belt usage in the vehicle. 
Dependent Variable: Presence of Serious Injuries in Struck Vehicle

\begin{tabular}{|c|c|c|c|c|c|c|c|c|c|}
\hline & $(1)$ & (2) & (3) & (4) & (5) & $(6)$ & $(7)$ & $(8)$ & $(9)$ \\
\hline Weight of Striking Vehicle (1000s of lbs) & $\begin{array}{c}0.00484 \\
(0.00014)\end{array}$ & $\begin{array}{c}0.07616 \\
(0.00207)\end{array}$ & $\begin{array}{c}0.00573 \\
(0.00017)\end{array}$ & $\begin{array}{c}0.08332 \\
(0.00242)\end{array}$ & $\begin{array}{c}0.00615 \\
(0.00019)\end{array}$ & $\begin{array}{c}0.08494 \\
(0.00260)\end{array}$ & $\begin{array}{c}0.00687 \\
(0.00021)\end{array}$ & $\begin{array}{c}0.00324 \\
(0.00020)\end{array}$ & $\begin{array}{c}0.00316 \\
(0.00020)\end{array}$ \\
\hline $\begin{array}{l}\text { Effect of } 1000 \mathrm{lb} \text { Increase in Striking Vehicle Weight/ } \\
\text { Percent Increase Over Sample Mean }\end{array}$ & $\begin{array}{c}0.00484 \\
18 \%\end{array}$ & $\begin{array}{c}0.00470 \\
18 \%\end{array}$ & $\begin{array}{c}0.00573 \\
19 \%\end{array}$ & $\begin{array}{c}0.00543 \\
18 \%\end{array}$ & $\begin{array}{c}0.00615 \\
19 \%\end{array}$ & $\begin{array}{c}0.00563 \\
17 \%\end{array}$ & $\begin{array}{c}0.00687 \\
20 \%\end{array}$ & $\begin{array}{c}0.00324 \\
20 \%\end{array}$ & $\begin{array}{c}0.00316 \\
20 \%\end{array}$ \\
\hline Weight of Struck Vehicle (1000s of lbs) & $\begin{array}{l}-0.00720 \\
(0.00013)\end{array}$ & $\begin{array}{l}-0.12392 \\
(0.00226)\end{array}$ & $\begin{array}{l}-0.00797 \\
(0.00016)\end{array}$ & $\begin{array}{l}-0.12874 \\
(0.00261)\end{array}$ & $\begin{array}{l}-0.00921 \\
(0.00018)\end{array}$ & $\begin{array}{l}-0.14280 \\
(0.00282)\end{array}$ & $\begin{array}{l}-0.00891 \\
(0.00020)\end{array}$ & $\begin{array}{l}-0.00479 \\
(0.00019)\end{array}$ & $\begin{array}{l}-0.00514 \\
(0.00019)\end{array}$ \\
\hline Striking Vehicle is Light Truck & $\begin{array}{c}0.00567 \\
(0.00022)\end{array}$ & $\begin{array}{c}0.08524 \\
(0.00322)\end{array}$ & $\begin{array}{c}0.00456 \\
(0.00027)\end{array}$ & $\begin{array}{c}0.06400 \\
(0.00367)\end{array}$ & $\begin{array}{c}0.00412 \\
(0.00029)\end{array}$ & $\begin{array}{c}0.05399 \\
(0.00392)\end{array}$ & $\begin{array}{c}0.00448 \\
(0.00032)\end{array}$ & $\begin{array}{c}0.00215 \\
(0.00030)\end{array}$ & $\begin{array}{c}0.00215 \\
(0.00030)\end{array}$ \\
\hline Struck Vehicle is Light Truck & $\begin{array}{l}-0.00033 \\
(0.00020)\end{array}$ & $\begin{array}{l}-0.00894 \\
(0.00343)\end{array}$ & $\begin{array}{l}-0.00212 \\
(0.00024)\end{array}$ & $\begin{array}{l}-0.03734 \\
(0.00389)\end{array}$ & $\begin{array}{l}-0.00075 \\
(0.00027)\end{array}$ & $\begin{array}{l}-0.02072 \\
(0.00414)\end{array}$ & $\begin{array}{c}0.00005 \\
(0.00029)\end{array}$ & $\begin{array}{l}-0.00069 \\
(0.00028)\end{array}$ & $\begin{array}{l}-0.00048 \\
(0.00028)\end{array}$ \\
\hline Specification & OLS & Probit & OLS & Probit & OLS & Probit & OLS & OLS & OLS \\
\hline Weather, Time, and County Fixed Effects & & & Yes & Yes & Yes & Yes & Yes & Yes & Yes \\
\hline Driver Characteristics & & & & & Yes & Yes & Yes & Yes & Yes \\
\hline City Fixed Effects & & & & & & & Yes & Yes & Yes \\
\hline Occupants and Seat Belt Usage & & & & & & & & & Yes \\
\hline Sample Size & $4,849,575$ & $4,849,575$ & $3,572,439$ & $3,571,255$ & $3,223,746$ & $3,223,344$ & $2,829,768$ & $1,470,596$ & $1,470,596$ \\
\hline
\end{tabular}

Notes: Each column represents a separate regression. The estimation sample is limited to collisions involving two vehicles. Parentheses contain standard errors clustered at the

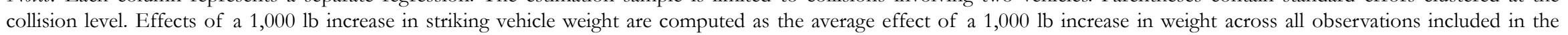

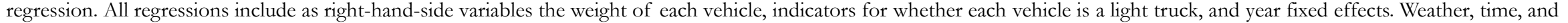
county fixed effects controls include rain, darkness, day of week (weekday versus weekend), Interstate highway, a quadratic in model year for each vehicle, and year, hour, and county

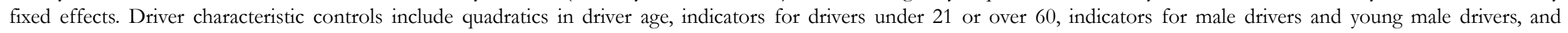
indicators for any seat belt usage in the vehicle. 
Dependent Variable: Presence of Fatalities in Struck Vehicle

Effect of $1000 \mathrm{lb}$ Increase in Striking Vehicle Weight/

Percent Increase Over Sample Mean

Weight of Striking Vehicle Squared

Weight of Striking Vehicle (1000s of lbs)

* Weight of Struck Vehicle

Specification

Sample Size
(1)

0.00099
$(0.00030)$

(2)

0.00083

(0.00031)

0.00101

$44 \%$

0.00000

$(0.00005)$

$(0.00005)$

0.00101

$43 \%$

0.00003

(0.00005)

$-0.00031$

(0.00007)

OLS

OLS

Probit

$-0.03802$

(0.00549)

0.40831

(0.04016)

0.00096

$41 \%$

$41 \%$

$-0.03843$

(0.00553)

0.00611

(0.00884)

Probit

$3,223,746$

$3,197,882$

$3,197,882$

Notes: Each column represents a separate regression. The estimation sample is limited to collisions involving two vehicles. Parentheses contain standard errors clustered at the collision level. Effects of a 1,000 lb increase in striking vehicle weight are computed as the average effect of a $1,000 \mathrm{lb}$ increase in weight across all observations included in the regression. All regressions include the following right-hand-side variables: weight of each vehicle, a quadratic in model year for each vehicle, indicators for whether each vehicle is a light truck, rain, darkness, day of week (weekday versus weekend), Interstate highway, quadratics in driver age, indicators for drivers under 21 or over 60, indicators for male drivers and young male drivers, indicators for any seat belt usage in the vehicle, and year, hour, and city fixed effects. 
Dependent Variable: Presence of Fatalities in Struck Vehicle

\begin{tabular}{|c|c|c|c|c|c|c|c|c|c|}
\hline & $(1)$ & (2) & (3) & (4) & (5) & (6) & $(7)$ & (8) & (9) \\
\hline Weight of Striking Vehicle (1000s of lbs) & $\begin{array}{c}0.00088 \\
(0.00010)\end{array}$ & $\begin{array}{c}0.11785 \\
(0.01203)\end{array}$ & $\begin{array}{c}0.00086 \\
(0.00012)\end{array}$ & $\begin{array}{c}0.10934 \\
(0.01391)\end{array}$ & $\begin{array}{c}0.00081 \\
(0.00013)\end{array}$ & $\begin{array}{c}0.10541 \\
(0.01583)\end{array}$ & $\begin{array}{c}0.00086 \\
(0.00014)\end{array}$ & $\begin{array}{c}0.00065 \\
(0.00019)\end{array}$ & $\begin{array}{c}0.00064 \\
(0.00019)\end{array}$ \\
\hline $\begin{array}{l}\text { Effect of } 1000 \mathrm{lb} \text { Increase in Striking Vehicle Weight/ } \\
\text { Percent Increase Over Sample Mean }\end{array}$ & $\begin{array}{c}0.00088 \\
42 \%\end{array}$ & $\begin{array}{l}0.00078 \\
37 \%\end{array}$ & $\begin{array}{c}0.00086 \\
36 \%\end{array}$ & $\begin{array}{c}0.00083 \\
32 \%\end{array}$ & $\begin{array}{c}0.00081 \\
32 \%\end{array}$ & $\begin{array}{c}0.00079 \\
28 \%\end{array}$ & $\begin{array}{c}0.00086 \\
35 \%\end{array}$ & $\begin{array}{c}0.00065 \\
42 \%\end{array}$ & $\begin{array}{c}0.00064 \\
41 \%\end{array}$ \\
\hline Weight of Struck Vehicle (1000s of lbs) & $\begin{array}{l}-0.00062 \\
(0.00011)\end{array}$ & $\begin{array}{l}-0.09830 \\
(0.01865)\end{array}$ & $\begin{array}{l}-0.00078 \\
(0.00014)\end{array}$ & $\begin{array}{l}-0.11463 \\
(0.02104)\end{array}$ & $\begin{array}{l}-0.00127 \\
(0.00016)\end{array}$ & $\begin{array}{l}-0.19317 \\
(0.02415)\end{array}$ & $\begin{array}{l}-0.00109 \\
(0.00017)\end{array}$ & $\begin{array}{l}-0.00079 \\
(0.00023)\end{array}$ & $\begin{array}{l}-0.00084 \\
(0.00024)\end{array}$ \\
\hline Striking Vehicle is Light Truck & $\begin{array}{c}0.00064 \\
(0.00014)\end{array}$ & $\begin{array}{c}0.08021 \\
(0.01863)\end{array}$ & $\begin{array}{c}0.00055 \\
(0.00017)\end{array}$ & $\begin{array}{c}0.06840 \\
(0.02044)\end{array}$ & $\begin{array}{c}0.00056 \\
(0.00019)\end{array}$ & $\begin{array}{c}0.06530 \\
(0.02345)\end{array}$ & $\begin{array}{c}0.00061 \\
(0.00020)\end{array}$ & $\begin{array}{c}0.00039 \\
(0.00030)\end{array}$ & $\begin{array}{c}0.00039 \\
(0.00030)\end{array}$ \\
\hline Struck Vehicle is Light Truck & $\begin{array}{l}-0.00022 \\
(0.00018)\end{array}$ & $\begin{array}{l}-0.03293 \\
(0.02969)\end{array}$ & $\begin{array}{l}-0.00031 \\
(0.00022)\end{array}$ & $\begin{array}{l}-0.05346 \\
(0.03178)\end{array}$ & $\begin{array}{c}0.00031 \\
(0.00024)\end{array}$ & $\begin{array}{c}0.00197 \\
(0.03484)\end{array}$ & $\begin{array}{c}0.00051 \\
(0.00026)\end{array}$ & $\begin{array}{l}-0.00014 \\
(0.00036)\end{array}$ & $\begin{array}{l}-0.00012 \\
(0.00036)\end{array}$ \\
\hline Specification & OLS & Probit & OLS & Probit & OLS & Probit & OLS & OLS & OLS \\
\hline Weather, Time, and County Fixed Effects & & & Yes & Yes & Yes & Yes & Yes & Yes & Yes \\
\hline Driver Characteristics & & & & & Yes & Yes & Yes & Yes & Yes \\
\hline City Fixed Effects & & & & & & & Yes & Yes & Yes \\
\hline Occupants and Seat Belt Usage & & & & & & & & & Yes \\
\hline Sample Size & 518,378 & 518,378 & 391,456 & 356,970 & 348,543 & 306,684 & 317,769 & 110,541 & 110,541 \\
\hline
\end{tabular}

Notes: Each column represents a separate regression. The estimation sample is limited to collisions involving three vehicles. Striking vehicle weight coefficients represent the average effect of increasing the weight of one striking vehicle by 1,000 pounds; they are the average of the coefficients on the first and second striking vehicles. Parentheses contain standard errors clustered at the collision level. Effects of a 1,000 lb increase in striking vehicle weight are computed as the average effect of a 1,000 lb increase in the weight of one striking vehicle across all observations included in the regression. All regressions include as right-hand-side variables the weight of each vehicle, indicators for whether each vehicle is a light truck, and year fixed effects. Weather, time, and county fixed effects controls include rain, darkness, day of week (weekday versus weekend), Interstate highway, a quadratic in model year for each vehicle, and year, hour, and county fixed effects. Driver characteristic controls include quadratics in driver age, indicators for drivers under 21 or over 60 , indicators for male drivers and young male drivers, and indicators for any seat belt usage in the vehicle. 


\begin{tabular}{|c|c|c|c|c|}
\hline Dependent Variable: & $\begin{array}{l}\text { HIC } \\
(1) \\
\end{array}$ & $\begin{array}{c}\mathrm{HIC}>700 \\
(2)\end{array}$ & $\begin{array}{l}\text { HIC } \\
(3) \\
\end{array}$ & $\begin{array}{c}\mathrm{HIC}>700 \\
(4)\end{array}$ \\
\hline Weight of Vehicle & $\begin{array}{c}17.7 \\
(16.1)\end{array}$ & $\begin{array}{c}0.024 \\
(0.018)\end{array}$ & $\begin{array}{c}38.2 \\
(43.5)\end{array}$ & $\begin{array}{c}0.018 \\
(0.040)\end{array}$ \\
\hline $\begin{array}{l}\text { Percentage Effect of } \\
1,000 \mathrm{lb} \text { Increase }\end{array}$ & $3.0 \%$ & $8.7 \%$ & $6.7 \%$ & $7.2 \%$ \\
\hline Sales Share Weighted & & & Yes & Yes \\
\hline Sample Size & 4,788 & 4,788 & 2,847 & 2,847 \\
\hline \multicolumn{5}{|c|}{$\begin{array}{l}\text { Notes: Each column represents a separate regression. The estimation sample in the first two } \\
\text { columns contains all NHTSA vehicle-to-barrier frontal crash test results. The estimation sample } \\
\text { in the last two columns contains only crash tests involving vehicles for which we have sales share } \\
\text { data. Parentheses contain standard errors clustered by vehicle make. All regressions include the } \\
\text { following right-hand-side variables: weight of tested vehicle, a quadratic in model year, a light } \\
\text { truck indicator, and a quadratic in collision speed. Sales share weighted regressions are weighted } \\
\text { by the tested vehicle's sales share for a given year. }\end{array}$} \\
\hline
\end{tabular}


Dependent Variable: Presence of Fatalities in Struck Vehicle

Average Vehicle Weight in Collision (1000s of lbs)

Effect of $1000 \mathrm{lb}$ Increase in Average Weight/

Percent Increase Over Sample Mean

Max Weight Difference Between Vehicles

Frontal Collisions Only

Sample Size
(1)

(2)

$-0.00110$

$(0.00108)$

$(0.00017)$

$-0.00004$

$-2 \%$

$200 \mathrm{lbs}$

$-0.00110$

$-19 \%$

$200 \mathrm{lbs}$

Yes

539,350

39,242
(3)

0.00003

(0.00023)

$-0.00181$

(0.00137)

$-0.00181$

$-35 \%$

$2 \%$

$100 \mathrm{lbs}$

$100 \mathrm{lbs}$

Yes

288,988

20,488

Notes: Each column represents a separate regression. The estimation sample is limited to collisions in which the difference in weight between the two vehicles is less than $200 \mathrm{lbs}$ (first two columns) or $100 \mathrm{lbs}$ (last two columns). Parentheses contain standard errors clustered at the collision level. Effects of a 1,000 lb increase in striking vehicle weight are computed as the average effect of a 1,000 lb increase in weight across all observations included in the regression. All regressions include the following right-hand-side variables: weight of each vehicle, a quadratic in model year for each vehicle, indicators for whether each vehicle is a light truck, rain, darkness, day of week (weekday versus weekend), Interstate highway, quadratics in driver age, indicators for drivers under 21 or over 60 , indicators for male drivers and young male drivers, indicators for any seat belt usage in the vehicle, and year, hour, and city fixed effects. 
Dependent Variable: Presence of Fatalities in Struck Vehicle

(1)

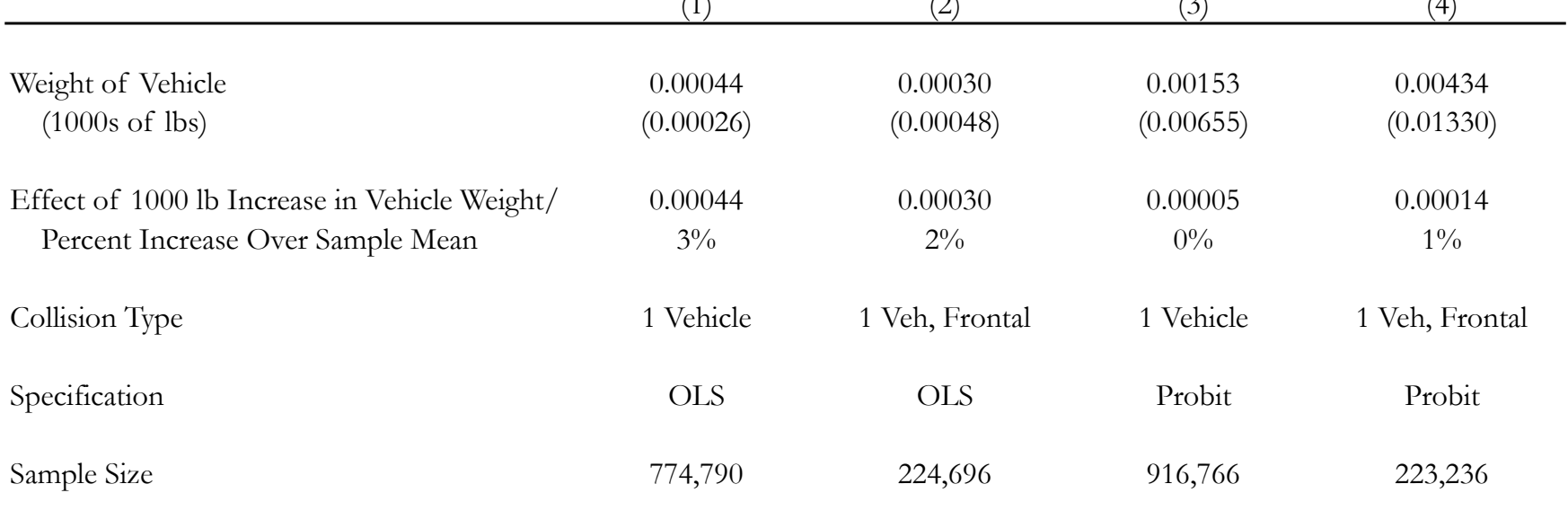

Notes: Each column represents a separate regression. The estimation sample is limited to collisions involving a single vehicle. Parentheses contain robust standard errors. Effects of a 1,000 lb increase in vehicle weight are computed as the average effect of a 1,000 lb increase in weight across all observations included in the regression. All regressions include the following right-handside variables: weight of vehicle, a quadratic in model year, indicators for whether a vehicle is a light truck, rain, darkness, day of week (weekday versus weekend), Interstate highway, quadratic in driver age, indicators for drivers under 21 or over 60 , indicators for male drivers and young male drivers, indicators for any seat belt usage in the vehicle, and year, hour, and either city fixed effects (OLS) or county fixed effects (probit). 
Table 9: Effect of Vehicle Weight on Fatalities Using Alternative Sources of Identification

Dependent Variable: Presence of Fatalities in Struck Vehicle

(1)

$\begin{array}{cc}0.00058 & 0.00072 \\ (0.00008) & (0.00016) \\ & \\ 0.00058 & 0.00072 \\ 47 \% & 58 \%\end{array}$

OLS

$1,011,982$
(3)

(4)

Weight of Striking Vehicle/

Additional Weight in Striking Vehicle (1000s of lbs)

Effect of 1000 lb Increase in Striking Vehicle Weight/ Percent Increase Over Sample Mean

Specification

Sample Size
$1,011,982$

\section{OLS w/Model FEs}

0.00064
$(0.00006)$
0.00064
$48 \%$

OLS

$1,475,762$
0.00062

(0.00026)

0.00062

$46 \%$

IV

Notes: Each column represents a separate regression. The estimation sample is limited to collisions involving two vehicles. Parentheses contain standard errors clustered at the collision level. Effects of a 1,000 lb increase in striking vehicle weight are computed as the average effect of a $1,000 \mathrm{lb}$ increase in weight across all observations included in the regression. All regressions include the following right-hand-side variables: weight of each vehicle, a quadratic in model year for each vehicle, indicators for whether each vehicle is a light truck, rain, darkness, day of week (weekday versus weekend), Interstate highway, quadratics in driver age, indicators for drivers under 21 or over 60 , indicators for male drivers and young male drivers, indicators for any seat belt usage in the vehicle, and year and hour fixed effects. OLS regressions with model fixed effects contain fixed effects for each vehicle model and county fixed effects. IV regressions contain city fixed effects and use the number of occupants in the striking vehicle times 164 lbs per occupant as the instrument for additional weight in the striking vehicle weight. 
Dependent Variable: Presence of Fatalities in Struck Vehicle

\begin{tabular}{|c|c|c|c|c|c|c|c|c|c|}
\hline & (1) & (2) & (3) & (4) & (5) & (6) & $(7)$ & (8) & $(9)$ \\
\hline Weight of Striking Vehicle (1000s of lbs) & $\begin{array}{c}0.00085 \\
(0.00005)\end{array}$ & $\begin{array}{c}0.16826 \\
(0.00881)\end{array}$ & $\begin{array}{c}0.00086 \\
(0.00006)\end{array}$ & $\begin{array}{c}0.15696 \\
(0.01010)\end{array}$ & $\begin{array}{c}0.00096 \\
(0.00007)\end{array}$ & $\begin{array}{c}0.17577 \\
(0.01187)\end{array}$ & $\begin{array}{c}0.00105 \\
(0.00007)\end{array}$ & $\begin{array}{c}0.00041 \\
(0.00007)\end{array}$ & $\begin{array}{c}0.00041 \\
(0.00007)\end{array}$ \\
\hline $\begin{array}{l}\text { Effect of } 1000 \text { lb Increase in Striking Vehicle Weight/ } \\
\text { Percent Increase Over Sample Mean }\end{array}$ & $\begin{array}{c}0.00085 \\
56 \%\end{array}$ & $\begin{array}{l}0.00084 \\
56 \%\end{array}$ & $\begin{array}{c}0.00086 \\
49 \%\end{array}$ & $\begin{array}{c}0.00087 \\
48 \%\end{array}$ & $\begin{array}{l}0.00096 \\
52 \%\end{array}$ & $\begin{array}{l}0.00094 \\
50 \%\end{array}$ & $\begin{array}{l}0.00105 \\
57 \%\end{array}$ & $\begin{array}{c}0.00041 \\
43 \%\end{array}$ & $\begin{array}{c}0.00041 \\
42 \%\end{array}$ \\
\hline Weight of Struck Vehicle (1000s of lbs) & $\begin{array}{l}-0.00032 \\
(0.00005)\end{array}$ & $\begin{array}{l}-0.06786 \\
(0.01014)\end{array}$ & $\begin{array}{l}-0.00047 \\
(0.00006)\end{array}$ & $\begin{array}{l}-0.08552 \\
(0.01142)\end{array}$ & $\begin{array}{l}-0.00117 \\
(0.00007)\end{array}$ & $\begin{array}{l}-0.20630 \\
(0.01281)\end{array}$ & $\begin{array}{l}-0.00111 \\
(0.00008)\end{array}$ & $\begin{array}{l}-0.00059 \\
(0.00008)\end{array}$ & $\begin{array}{l}-0.00061 \\
(0.00008)\end{array}$ \\
\hline
\end{tabular}

\begin{tabular}{|c|c|c|c|c|c|c|c|c|c|}
\hline Specification & OLS & Probit & OLS & Probit & OLS & Probit & OLS & OLS & OLS \\
\hline Weather, Time, and County Fixed Effects & & & Yes & Yes & Yes & Yes & Yes & Yes & Yes \\
\hline Driver Characteristics & & & & & Yes & Yes & Yes & Yes & Yes \\
\hline City Fixed Effects & & & & & & & Yes & Yes & Yes \\
\hline Occupants and Seat Belt Usage & & & & & & & & & Yes \\
\hline Sample Size & $2,801,186$ & $2,801,186$ & $2,012,046$ & $1,962,129$ & $1,815,558$ & $1,771,574$ & $1,578,094$ & 824,544 & 824,544 \\
\hline
\end{tabular}

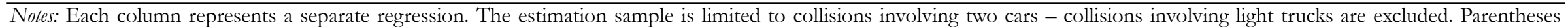

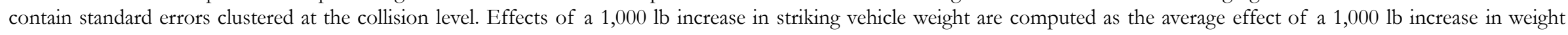

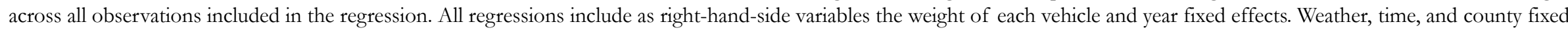

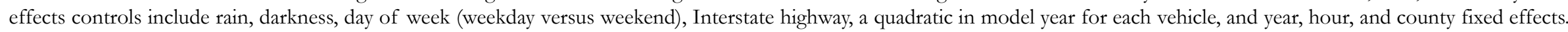

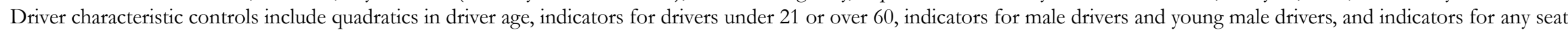
belt usage in the vehicle. 
Table A2: Effect of Vehicle Weight on Fatalities for States with High and Low Missing Weight Data

Dependent Variable: Presence of Fatalities in Struck Vehicle

Effect of $1000 \mathrm{lb}$ Increase in Striking Vehicle Weight/ Percent Increase Over Sample Mean

Percent of Accidents with Missing Weight Data

Weather, Time, Driver, and City Controls

Sample Size
(1)

0.00046
$(0.00005)$

(2)

0.00115

(0.00006)

0.00046

$46 \%$

$24 \%$

$41 \%$

0.00115

$44 \%$

$24 \%$

Yes

0.00063

$51 \%$

0.00063

(0.00007)

0.00135

(0.00008)

0.00135

$44 \%$

$41 \%$

Yes

$2,144,719$

$2,704,856$

$1,103,620$

$1,726,148$

Notes: Each column represents a separate regression. The estimation sample is limited to collisions involving two vehicles Columns (1) and (3) are estimated using data from states in which a low proportion of observations are missing weight data (Ohio, Washington, and Wyoming). Columns (2) and (4) are estimated using data from states in which a high proportion of observations are missing weight data (Florida, Kansas, Kentucky, Maryland, and Missouri). Parentheses contain standard errors clustered at the collision level. All regressions include as right-hand-side variables the weight of each vehicle, indicators for whether each vehicle is a light truck, and year fixed effects. Weather, time, driver, and city controls include rain, darkness, day of week (weekday versus weekend), Interstate highway, quadratics in driver age, indicators for drivers under 21 or over 60 , indicators for male drivers and young male drivers, indicators for any seat belt usage in the vehicle, and year, hour, and city fixed effects. 